\title{
Perfluorobicyclo[2.2.0]hex-1(4)-ene as unique partner for Diels-Alder reactions with benzene: a density functional theory study
}

\author{
Agnieszka Kącka-Zych ${ }^{1}$ (1) Patricia Pérez ${ }^{2}$
}

Received: 1 November 2020 / Accepted: 29 December 2020 / Published online: 22 January 2021

(c) The Author(s) 2021

\begin{abstract}
The mechanism of the Diels-Alder reactions between perfluorobicyclo[2.2.0]hex-1(4)-ene (1a) and bicyclo[2.2.0]hex-1(4)ene (1b) with benzene (2a) and naphthalene (2b) has been studied within the density functional theory at the MPWB1K/6$311 \mathrm{G}(\mathrm{d}, \mathrm{p})$ level. The bonding pattern in these reactions is analyzed in the topology of the electron localization function within the bonding evolution theory perspective. The bonding electron density changes along the reaction paths reveal that the $\mathrm{C}-\mathrm{C}$ bond formation takes place through a synchronous and non-concerted one-step mechanism and proceeds with a moderate activation energy. The reactivity order with $\mathbf{1 a}$ is $\mathbf{2 a - 2} \mathbf{2}$. The reactions begin by the rupture of the double bond in the strained 1a-b molecules, and then two pseudoradical centers at the 1a-b fragments are created. Finally, at the same time, two new single bonds are formed in the cycloaddition products. The TSs proceed with high global electron density transfer providing a polar character at these reactions.
\end{abstract}

Keywords Benzene $\cdot$ Diels-alder reaction $\cdot$ Density functional theory $\cdot$ Molecular electron density theory $\cdot$ Molecular mechanism

\section{Introduction}

The extremely low, potential reactivity of the parent benzene in the addition processes is generally known as the logical consequence of the tendency for retention of ideal-aromatic nature of their six-membered ring. However, the arene systems with some disturbances in their aromatic nature show some tendency to participate in cycloaddition reactions with

Supplementary information The online version contains supplementary material available at (https://doi.org/10.1007/ s00214-020-02709-6).

Agnieszka Kącka-Zych

agnieszka.kacka-zych@pk.edu.pl

$\triangle$ Patricia Pérez

p.perez@unab.cl

1 Institute of Organic Chemistry and Technology, Cracow University of Technology, Warszawska 24, 31-155 Cracow, Poland

2 Facultad de Ciencias Exactas, Departamento de Ciencias Químicas, Computational and Theoretical Chemistry Group, Universidad Andres Bello, Av. República 498, 8370146 Santiago, Chile suitably strong reactive partners. This tendency correlates with the disturbance of the aromatic nature of the molecule.

So, many examples of Diels-Alder (DA) reactions involving furan as 1,3-diene analogue have been described [1-6]. In the case of DA cycloadditions of furan with electrophilic activated ethenes, these type reactions may proceed under relatively mild conditions. For example, DA reaction of furan with (E)-3,3,3-trichloro-1-nitroprop-1-ene [2] (global electrophilicity is equal to $3.27 \mathrm{eV}$ ) [7] proceeds easily even at the room temperature (Scheme 1).

Carbocyclic aromatic systems are less reactive. For example, anthracene reacts with the mentioned above (E)-3,3,3trichloro-1-nitroprop-1-ene at $180{ }^{\circ} \mathrm{C}$ in $19 \mathrm{~h}$ (Scheme 2) [8].

Less, than in the case of anthracene disordered aromatic system, observed in the case of naphthalene, require more dramatic conditions. For example, naphthalene reacts with the N-phenyl-maleimide only under high-pressure conditions. Despite high pressure as well as higher temperature, the conversion of addends is realized in $80 \mathrm{~h}$ (Scheme 3) [9].

For the contrast, with dienophiles mentioned above under conditions described, the benzene does not react via DA cycloaddition scheme. Some examples DA reactions of benzene are known, but under photochemical conditions $[10,11]$. On the other hand, some strong electrophilic and 
Scheme 1 DA reaction of furan with (E)-3,3,3-trichloro-1-nitroprop-1-ene [2]
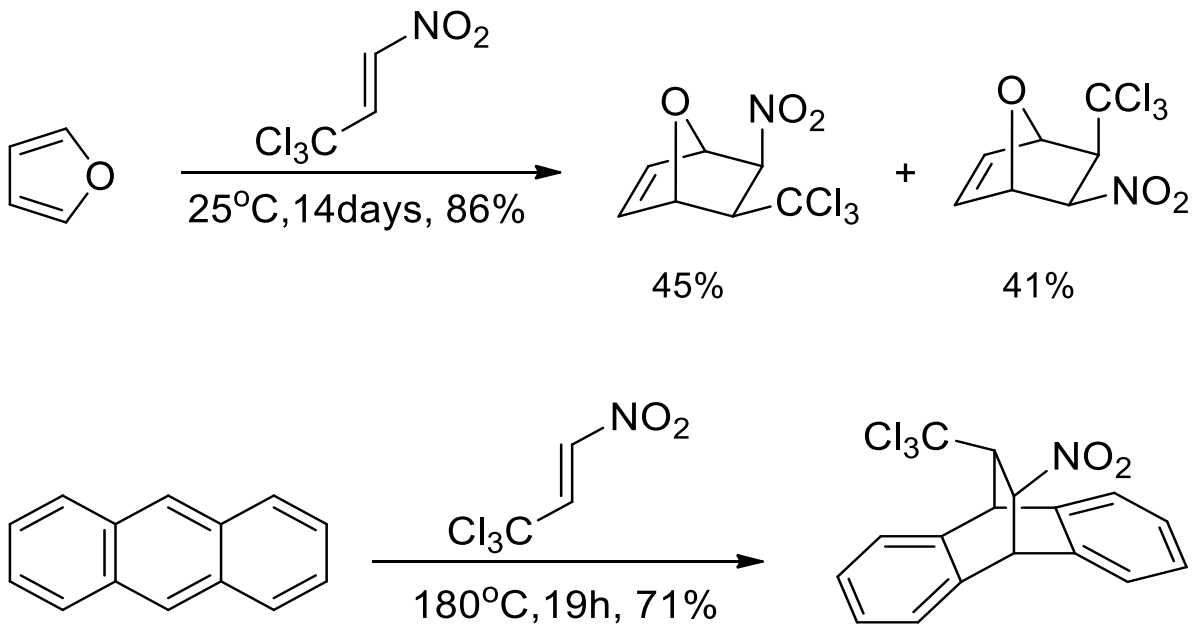

Scheme 2 DA reaction between anthracene and (E)-3,3,3trichloro-1-nitroprop-1-ene [8]

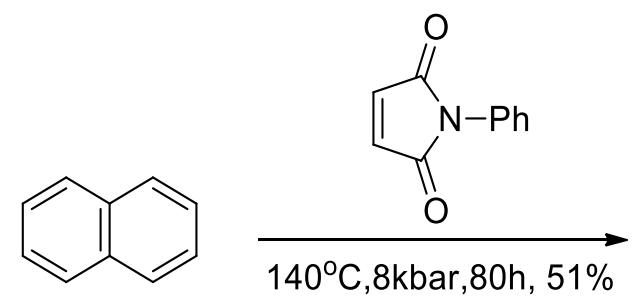

Scheme 3 DA reaction maleimide [9] naphthalene with N-phenyl-

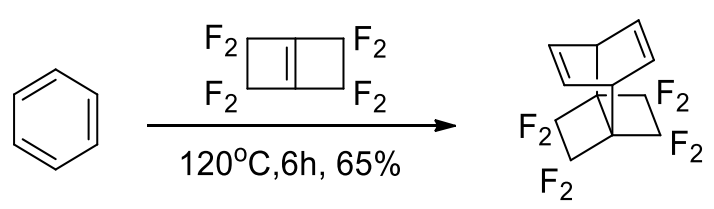

Scheme 4 DA reaction of perfluorobicyclo[2.2.0]hex-1(4)-ene with benzene [12]

extremely active alkenes such as 2-nitroprop-1-ene can react with benzene. There are, however, not DA cycloadditions, but $\mathrm{SE}_{\mathrm{Ar}}$ reaction. Thermal allowed DA reactions involving benzene ring are extremely difficult and with satisfactory yield are known regarding for only one example. This interesting process is based on the perfluorobicyclo[2.2.0]hex-1(4)-ene and is determined by presence of fluorine atoms with highly strained of $>\mathrm{C}=\mathrm{C}<$ moiety (Scheme 4) [12].

On the other hand, Houk and coworkers considered on the basis of quantum chemical calculations the stepwise, biradical mechanism of the hypothetical cycloaddition of benzene with allene. In this case, the biradical exists on the potential energy hypersurface (PES) as the common intermediate for [2+2] and [4+2] processes. Unfortunately, this study was not supported by experimental study due to tendency of allene systems for the rapid dimerization [13]. Recently, Bickelhaupt and coworkers studied the effect of alkali cations catalyzing aromatic DA reactions [14]. The catalytic effect in the DA reaction barrier decreases in the order $\mathrm{M}^{+}=$none $>\mathrm{Cs}>\mathrm{Rb}>\mathrm{K}>\mathrm{Li}$. The authors conclude that augmented reactivity of the metal-catalyzed DA reactions is due to reduction of Pauli repulsions between benzene cation and acetylenes within the context of the activation strain model (ASM) [15]. More recently, it was reported, within the so-called molecular electron density theory (MEDT) scheme, a theoretical study of the lithium cation-catalyzed benzene DA reactions, which showed that the coordination of $\mathrm{Li}^{+}$to the complex of benzene with crown ether improved the electrophilic character of benzene and the feasibility of the DA reaction [16]. It is important to mention that the polar Diels-Alder (P-DA), as will see later, takes relevance when the electrophilic/ nucleophilic interactions occur at the TS controlling the feasibility of the DA reactions [17]. Recently, other theoretical study using MEDT [18] scheme of a series of DA reactions of ethylene with aza aromatic compounds [19] finds an enhancement of the reactivity of the latter species mainly due to the loss of their aromatic character that destabilizes the reagents.

The aim of this work is to enhance the understand and the description of bonding breaking/forming involved on the mechanism of the DA reactions, in particular in cycloadditions involving very stable reagents as aromatic species; hence, we present a complete study of the DA reaction given by a strong electrophile as perfluorobicyclo[2.2.0] 
hex-1(4)-ene 1a with benzene $\mathbf{2 a}$ and naphthalene $\mathbf{2 b}$ and, on the other hand, the corresponding DA reaction mechanism given by the marginal electrophile as bicyclo[2.2.0] hex-1(4)-ene 1b with benzene $\mathbf{2 a}$ and naphthalene $\mathbf{2 b}$. To achieve that will be used known theoretical tools defined within the context of the density functional theory (DFT) $[20,21]$. A qualitative bonding evolution theory (BET) [22] analysis along these DA reactions is performed to characterize these bonding changes.

\section{Computational details}

All calculations associated with the P-DA reactions were performed using the GAUSSIAN 16 package [23] in the Prometheus computer cluster of the CYFRONET regional computer center in Cracow. The geometries of all reactants, transition state structures (TSs) and products of the reactions were fully optimized using the MPWB1K [24] functional together with the 6-311G(d,p) basis set. Stationary points were characterized by frequency calculations. All reactants and products had positive Hessian eigenvalues. All TSs had only one negative eigenvalue in their diagonalized Hessian matrices, and their associated eigenvectors were confirmed to correspond to the motion along the reaction coordinate under consideration. TSs were located using the (QST2) algorithm. Intrinsic reaction coordinate (IRC) calculations [25] were performed in all cases to verify that the located TSs are connected to the corresponding minimum stationary points associated with reactants, products and intermediates. The solvent effects of benzene were simulated using a relatively simple self-consistent reaction field (SCRF) [26-28] based on the polarizable continuum model (PCM) of Tomasi's group [29, 30]. The stability of the wave function for all reagents, products and TSs, and the points of the IRC for the most favorable pathway has been checked. The values of energies, enthalpies, entropies and Gibbs free energies were calculated for temperature $393 \mathrm{~K}$.

Global reactivity indices at the ground states (GS) of the reagents and products, within of the conceptual density functional theory (CDFT) [31, 32], were calculated at the B3LYP/6-31G(d) level. The global electron density transfer (GEDT) [33] values were calculated as the sum of the natural atomic charges $(q)$, obtained by a natural population analysis (NPA) [34, 35], by the equation: GEDT (f) $=\sum_{q \in f} q$, for all atoms belonging to each $\mathbf{f}$ fragment (i.e., electrophile and nucleophile) of the TSs at the same level of theory.

Global electronic properties of the reactants were estimated according to the equations recommended in references [31, 32]. In particular, the electronic chemical potentials $(\mu)$ and chemical hardness $(\eta)$ were evaluated in terms of one-electron energies of FMO ( $\mathrm{E}_{\text {Hомо }}$ and $\mathrm{E}_{\mathrm{LUMO}}$ ) using the following equations: $\mu \approx\left(\mathrm{E}_{\mathrm{HOMO}}+\mathrm{E}_{\mathrm{LUMO}}\right) / 2$, $\eta \approx \mathrm{E}_{\text {LUMO_- }} \mathrm{E}_{\text {Hомо }}$. Next, the values of $\mu$ and $\eta$ were used for the calculation of global electrophilicity $(\omega)$ according to the formula: $\omega=\mu^{2} / 2 \eta$ [36]. Subsequently, global nucleophilicity $(N)$ [37] can be expressed in terms of the equation: $N=\mathrm{E}_{\text {HOMO_}} \mathrm{E}_{\text {HOMO(tetracyanoethylene) }}$, where tetracyanoethylene is used as reference. Local reactivity indices, electrophilic $P_{k}^{+}$and nucleophilic $P_{k}^{-}$Parr functions [38] were obtained from the changes of atomic spin density (ASD) of the reagents to identify electrophilic and nucleophilic centers in the molecules.

Electron localization function (ELF) [39] studies were performed with the TopMod package [40] considering the standard cubical grid of step size of 0.1 Bohr. The bonding changes along corresponding reactions were analyzed, according to the bonding evolution theory (BET) [22], by performing the topological analysis of the ELF for 198 nuclear configurations along the IRC path. The ELF molecular geometries and basin attractor positions were visualized using the GaussView program [41]. ELF localization domains were represented by using the ParaView software at an isovalue of 0.75 a.u [42, 43]. A similar approach has been successfully used to explain the mechanism of different types of reactions [44-50].

\section{Results and discussion}

The present study is organized as follows: In Sect. 3.1, an analysis of the electronic structure and ELF topological analysis of reagents is performed. Section 3.2 contains an analysis of the CDFT reactivity indices of the reagents involved in the DA reactions of perfluorobicyclo[2.2.0]hex-1(4)-ene 1a, bicyclo[2.2.0] hex-1(4)-ene 1b and 2a-b. In Sect. 3.3, the reaction profiles associated with the DA reactions of $\mathbf{1 a - b}$ with 2a-b are analyzed. Finally, in Sect. 3.4 a BET study of the DA reactions between perfluorobicyclo[2.2.0]hex-1(4)ene $\mathbf{1 a}$ and $\mathbf{2 a - b}$ is performed.

\subsection{ELF topological analysis of reagents}

Quantum chemical analysis of Becke and Edgecombe's ELF [38] allows the electronic structure to be determined by a direct combination of electronic density distribution and chemical structure. Therefore, in order to characterize the electronic structures of perfluorobicyclo[2.2.0]hex-1(4)-ene 1a, bicyclo[2.2.0]hex-1(4)-ene 1b, benzene 2a and naphthalene $\mathbf{2 b}$, a topological analysis of the ELF of reagents was first performed. Lewis-like structures, ELF localization domains and basin attractor positions, together with the most significant valence basin populations, are shown in Fig. 1 and Fig. 2.

ELF topological analysis of perfluorobicyclo[2.2.0] hex-1(4)-ene 1a, in the most important region, shows the 
Fig. 1 MPWB1K/6-311G(d,p)

localization domains

(isovalue $=0.75$ ) and basin

attractor positions together with the most significant valence basin populations and proposed Lewis-like structures of perfluorobicyclo[2.2.0]hex-

1(4)-ene 1a and bicyclo[2.2.0] hex-1(4)-ene 1b

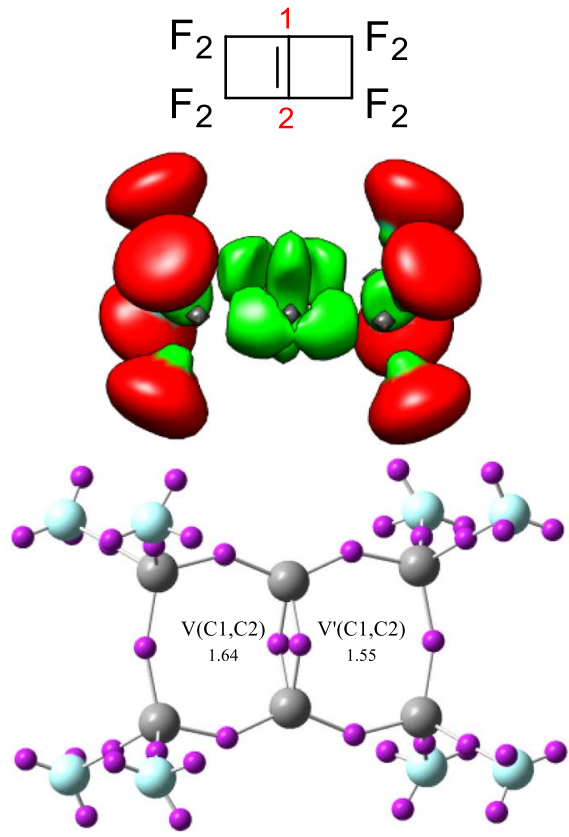

$1 \mathbf{a}$
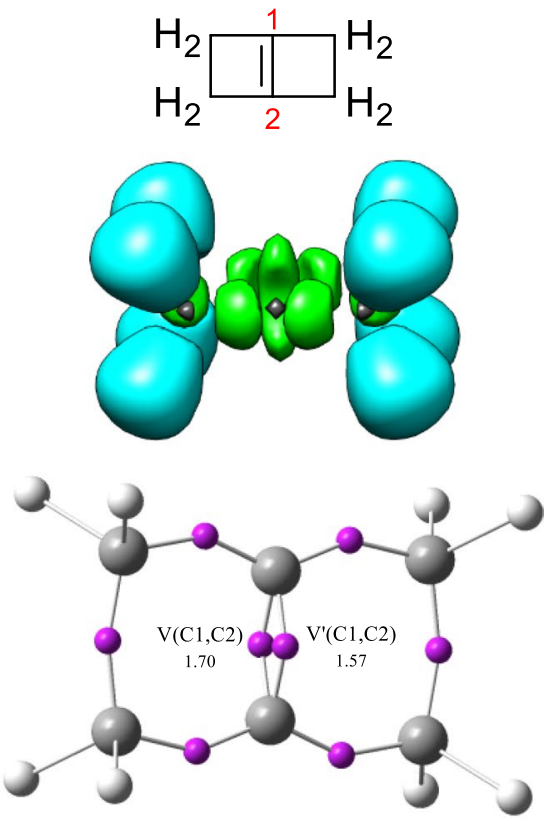

$1 b$
Fig. 2 MPWB1K/6-311G(d,p) localization domains (isovalue $=0.75$ ) and basin attractor positions together with the most significant valence basin populations and proposed Lewis-like structures of benzene $\mathbf{2 a}$ and naphthalene $\mathbf{2 b}$

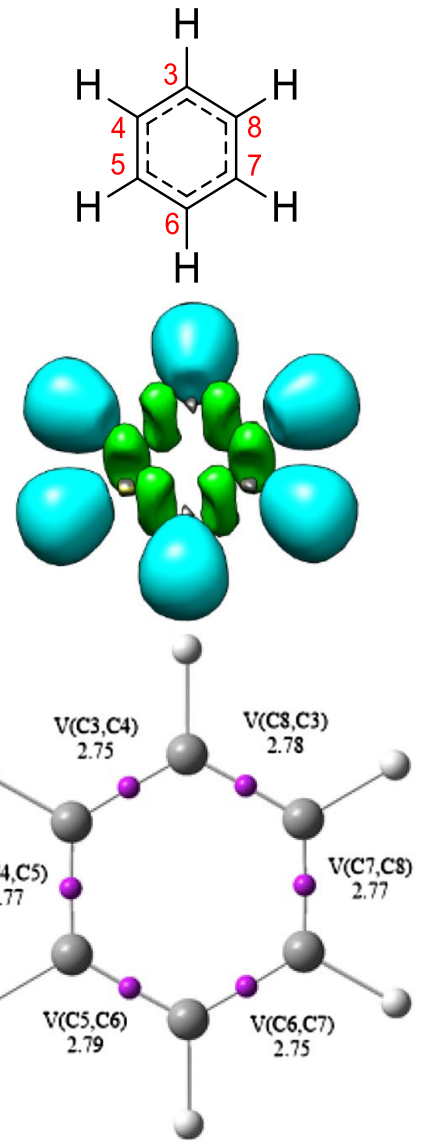

2a<smiles>c1ccc2ccccc2c1</smiles>
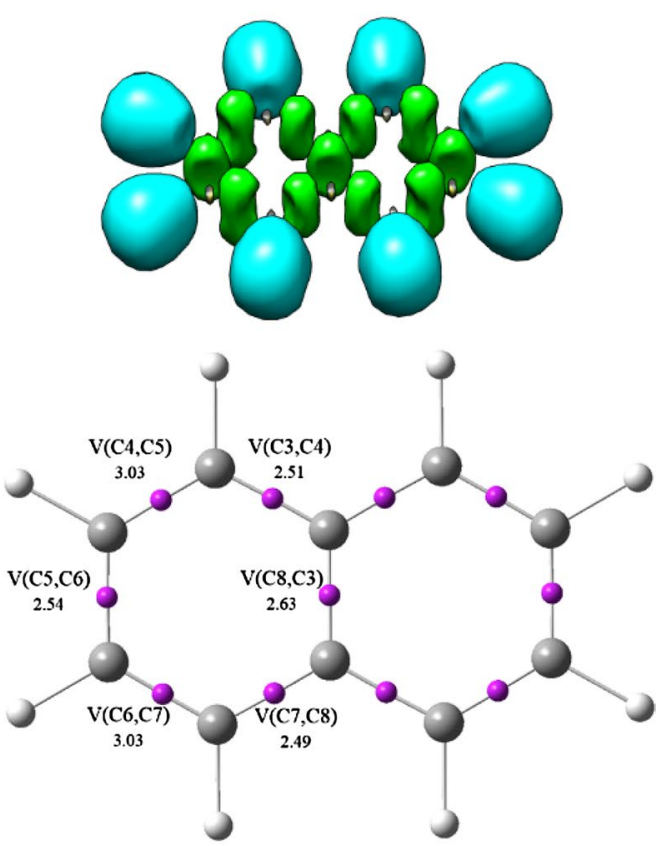

2b 
presence of two $\mathrm{V}(\mathrm{C} 1, \mathrm{C} 2)$ and $\mathrm{V}^{\prime}(\mathrm{C} 1, \mathrm{C} 2)$ disynaptic basins integrating $1.64 \mathrm{e}$ and $1.55 \mathrm{e}$, respectively. In the bicyclo[2.2.0]hex-1(4)-ene 1b, we also find, in the most important region, $\mathrm{V}(\mathrm{C} 1, \mathrm{C} 2)$ and $\mathrm{V}^{\prime}(\mathrm{C} 1, \mathrm{C} 2)$ disynaptic basins integrating a total population of $3.27 \mathrm{e}$. These disynaptic basins are associated with $\mathrm{C} 1-\mathrm{C} 2$ double bonds in 1a and 1b molecules.

On the other hand, an ELF topological analysis of benzene 2a shows the presence of six $\mathrm{V}(\mathrm{C} 3, \mathrm{C} 4), \mathrm{V}(\mathrm{C} 4, \mathrm{C} 5)$, $\mathrm{V}(\mathrm{C} 5, \mathrm{C} 6), \mathrm{V}(\mathrm{C} 6, \mathrm{C} 7), \mathrm{V}(\mathrm{C} 7, \mathrm{C} 8)$ and $\mathrm{V}(\mathrm{C} 8, \mathrm{C} 3)$ disynaptic basins integrating in all cases $2.75-2.79$ e (Fig. 2). These disynaptic basins are associated with partial double bonds in benzene 2a. In turn, in the case of naphthalene $\mathbf{2 b}$, we find three $\mathrm{V}(\mathrm{C} 4, \mathrm{C} 5), \mathrm{V}(\mathrm{C} 6, \mathrm{C} 7)$ and $\mathrm{V}(\mathrm{C} 8, \mathrm{C} 3)$ disynaptic basins integrating $3.03 \mathrm{e}, 3.03$ and 2.63 e, respectively. These disynaptic basins are related to partial double bond, while the other three $\mathrm{V}(\mathrm{C} 3, \mathrm{C} 4), \mathrm{V}(\mathrm{C} 5, \mathrm{C} 6)$ and $\mathrm{V}(\mathrm{C} 7, \mathrm{C} 8)$ disynaptic basins are associated with single bonds.

\subsection{Analysis of the global and local CDFT Reactivity Indices at the GS of the Reagents}

In order to understand the participation of these reagents in the DA reactions, an analysis of the global indices at the ground states (GS) of these species was performed, defined within the context of the CDFT [31,32] and calculated at the B3LYP/6-31G(d) level of theory. In Table 1 are collected electronic chemical potential $\mu$, chemical hardness $\eta$, global electrophilicity $\omega$, and global nucleophilicity $N$ values of the GS of the reagents. The order is given in decreasing electrophilicity values.

The electronic chemical potential [21] $\mu$ of $\mathbf{2 a}$ is -3.30 and that of $\mathbf{2 b}$ is $-3.37 \mathrm{eV}$, which are higher than that of $\mathbf{1 a}$, $\mu=-5.38 \mathrm{eV}$, indicating that GEDT [33] in these cycloaddition reactions will proceed from benzene, naphthalene and butadiene toward 1a. Note that $\mathbf{1 b}$ presents the highest value of $\mu(-2.46 \mathrm{eV})$.

It can be seen that the electrophilicity [36] $\omega$ and nucleophilicity [37] $N$ indices of $\mathbf{1 a}$ are 2.08 and $0.26 \mathrm{eV}$, respectively, classifying it as a strong electrophile and marginal nucleophile within the electrophilicity [50] and nucleophilicity [51] scales. This behavior predicts a P-DA reaction with strong and moderate nucleophiles. Instead, $\mathbf{1 b}$ presents $\omega=0.41 \mathrm{eV}$ and $N=2.95 \mathrm{eV}$, being a marginal electrophile and in the borderline of moderate nucleophile. Clearly, the

Table 1 Gas phase B3LYP/6$31 \mathrm{G}(\mathrm{d})$ electronic chemical potential $\mu$, chemical hardness $\eta$, global electrophilicity $\omega$ and global nucleophilicity $N$, in $\mathrm{eV}$, for the studied reagents presence of four fluorine centers in 1a makes it more electrophilic than $\mathbf{1 b}$.

On the other hand, the electrophilicity $\omega$ and nucleophilicity $N$ indices of benzene $\mathbf{2 a}$ are $0.80 \mathrm{eV}$ and $2.42 \mathrm{eV}$, being classified in the borderline of moderate electrophile and moderate nucleophile. The reactivity indices of two fused benzene rings to give naphthalene $\mathbf{2 b}$, strongly increases both the electrophilicity and nucleophilicity, $\omega=1.28 \mathrm{eV}$ and $*=3.33 \mathrm{eV}$, predicting feasible participation in P-DA reactions as a nucleophilic species. Additionally, note that $\mathbf{1 a}$ and $\mathbf{1 b}$ are strained species, while $\mathbf{2} \mathbf{a}$ and $\mathbf{2} \mathbf{b}$ are recognized aromatic species.

It is well known that in polar processes, the nucleophilic species transfer electron density toward electrophilic ones. The electron density changes on the electrophile and nucleophile can be sensed by the nucleophilic $P_{k}^{-}$and electrophilic $P_{k}^{+}$Parr functions [38], which are good predictors for local reactivity in polar processes. The electrophilic $P_{k}^{+}$and the nucleophilic $P_{k}^{-}$and Parr functions for the GS of the reagents are gathered in Table 2 and Fig. 3.

An analysis of the electrophilic $P_{k}^{+}$Parr functions of 1a indicates that $\mathrm{C} 1$ and $\mathrm{C} 2$ are the most electrophilic center in the molecule, $P_{k}^{+}=0.49$, while all $\mathrm{C}_{\mathrm{F}}$ centers show negligible electrophilic and nucleophilic character. The electrophilic $P_{k}^{+}$and nucleophilic $P_{k}^{-}$Parr functions of $\mathbf{1 b}$, at $\mathrm{C} 1$ and $\mathrm{C} 2, P_{k}^{+}=0.49$ and $P_{k}^{-}=0.44$, show electrophilic and nucleophilic behavior predicting that this reagent will react

Table 2 Gas phase $P_{k}^{+}$and nucleophilic $P_{k}^{-}$and Parr functions of the GS of the reagents at the present study

\begin{tabular}{|c|c|c|c|}
\hline & & $\begin{array}{l}\text { Electrophilic Parr func- } \\
\text { tion } \\
P_{k}^{+}\end{array}$ & $\begin{array}{l}\text { Nucleophilic } \\
\text { Parr function } \\
P_{k}^{-}\end{array}$ \\
\hline \multirow[t]{3}{*}{$1 \mathrm{a}$} & $\mathrm{C} 1$ & 0.49 & 0.05 \\
\hline & $\mathrm{C} 2$ & 0.49 & 0.05 \\
\hline & $\mathrm{C}_{\mathrm{F}}$ & 0.00 & 0.09 \\
\hline \multirow[t]{3}{*}{$1 b$} & $\mathrm{C} 1$ & 0.49 & 0.44 \\
\hline & $\mathrm{C} 2$ & 0.49 & 0.44 \\
\hline & $\mathrm{C}_{\mathrm{H}}$ & 0.04 & 0.00 \\
\hline \multirow[t]{6}{*}{$2 a$} & $\mathrm{C} 3$ & 0.47 & 0.48 \\
\hline & C6 & 0.47 & 0.48 \\
\hline & $\mathrm{C} 4$ & 0.03 & 0.02 \\
\hline & C5 & 0.03 & 0.02 \\
\hline & $\mathrm{C} 7$ & 0.03 & 0.02 \\
\hline & $\mathrm{C} 8$ & 0.03 & 0.02 \\
\hline \multirow[t]{6}{*}{$2 b$} & $\mathrm{C} 4$ & 0.25 & 0.26 \\
\hline & $\mathrm{C} 7$ & 0.25 & 0.26 \\
\hline & $\mathrm{C} 3$ & -0.07 & -0.08 \\
\hline & $\mathrm{C} 8$ & -0.07 & -0.08 \\
\hline & C5 & 0.05 & 0.04 \\
\hline & C6 & 0.05 & 0.04 \\
\hline
\end{tabular}


Fig. 3. 3D representations of the ASD of the radical anion $\mathbf{1 a}^{-\boldsymbol{}}$ and $\mathbf{1 \mathbf { b } ^ { - }}$ and the radical cation $\mathbf{2} \mathbf{a}^{\cdot+}$ and $\mathbf{2} \mathbf{b}^{++}$, together with the electrophilic $P_{k}^{+}$Parr functions of $\mathbf{1 a - b}$ and the nucleophilic $P_{k}^{-}$Parr functions of $\mathbf{2 a}-\mathbf{b}$

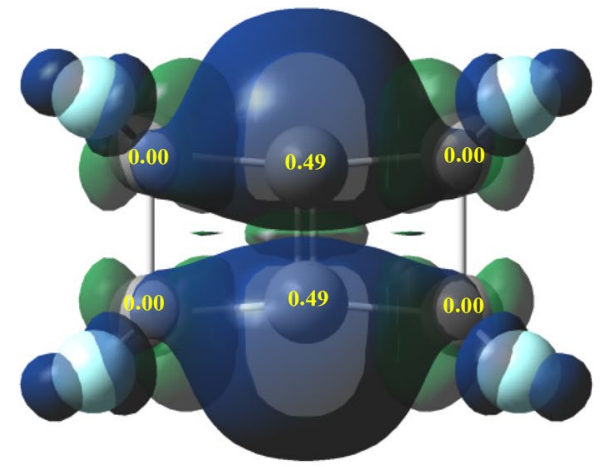

$1 a^{--}$

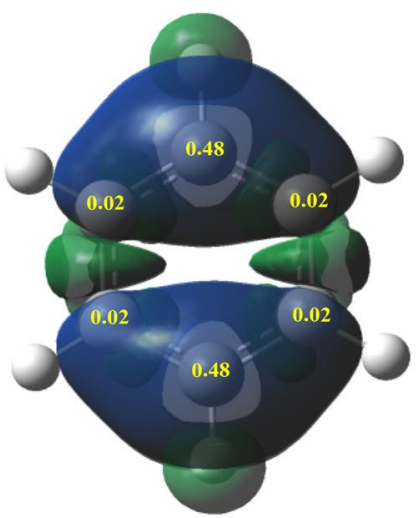

$2 a^{++}$

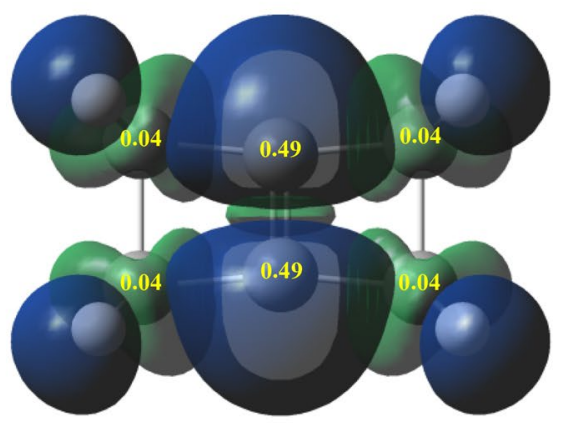

$1 b^{-}$

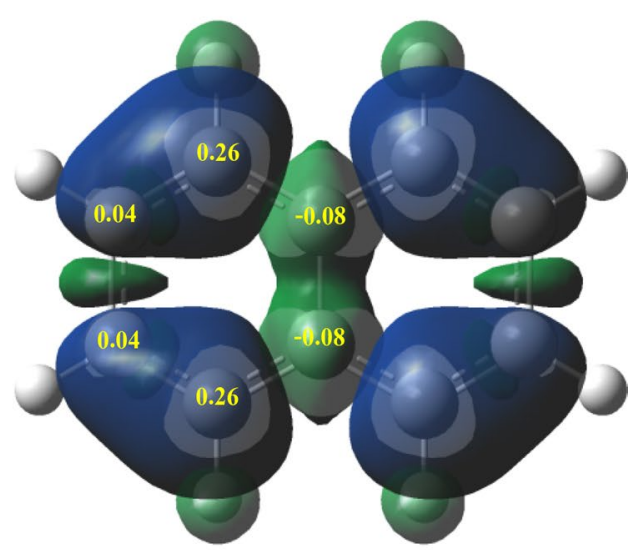

$\mathbf{2 b}^{\cdot+}$ with a strong nucleophiles or electrophiles via a polar reaction. The local electrophilic and nucleophilic character of $\mathrm{C}_{\mathrm{H}}$ is insignificant.

The nucleophilic $P_{k}^{-}$Parr functions of $\mathbf{2 a}$ at C3 and C6, $P_{k}^{-}=0.48$, show the strong nucleophilic character at these centers. Note that electrophilic $P_{k}^{+}$values at the same centers are very similar; however, the nucleophilic character of 2a, shown in Table $1(\mathrm{~N}=2.42 \mathrm{eV})$, predicts that its reactive centers will have nucleophilic character in polar reactions. It is worth to mention that centers C4, C5, C7 and C8 (see Table 2) develop unimportant nucleophilic/electrophilic character.

For 2b, nucleophilic $P_{k}^{-}$Parr functions at $\mathrm{C} 4$ and $\mathrm{C} 7$, $P_{k}^{-}=0.26$, presenting the nucleophilic character in agreement with the high value of nucleophilicity, $\mathrm{N}=3.33 \mathrm{eV}$. Very similar electrophilic $P_{k}^{+}$values at $\mathrm{C} 4$ and $\mathrm{C} 7, P_{k}^{+}=0.25$, were obtained. Their local electrophilic character is lower than $\mathbf{2} \mathbf{a}$ due to the presence of more centers in the two fused benzene rings. The electrophilic/nucleophilic Parr functions at the other centers of $\mathbf{2} \mathbf{b}$ are negligible.

In summary, along polar reactions, the most favorable process will be associated with the two centers interaction between the most electrophilic center of $\mathbf{1 a}$ and the most nucleophilic centers of $\mathbf{2} \mathbf{a}-\mathbf{2} \mathbf{b}$. Note that $\mathbf{1 a}$ and $\mathbf{1 b}$ are strained reagents; therefore, it is expected that they react more favorably releasing that strain. On the other hand, 2a and $\mathbf{2 b}$ are aromatic species, so it is expected they react with their partners minimizing that loss.

\subsection{Study of the DA reaction between $1 a-b$ and $2 a-b$}

The P-DA reaction between perfluorobicyclo[2.2.0]hex-1(4)ene $\mathbf{1 a}$ and $\mathbf{2 a - b}$ takes place through a one-step mechanism (see Scheme 5). The MPWB1K(PCM)/6-311G(d,p) relative enthalpies, Gibbs free energy and entropies of the stationary points in the DA reactions of perfluorobicyclo[2.2.0] hex-1(4)-ene 1a with $\mathbf{2 a - b}$ are given in Table 3 and in Supplementary Information (Tables S2 and S4). In turn, total electronic energies in benzene and gas phase for DA reactions 1a-b with $\mathbf{2 a - b}$ are given in Supplementary Information (Tables S1 and S3).

The reaction between perfluorobicyclo[2.2.0]hex1(4)-ene $\mathbf{1 a}$ and benzene $\mathbf{2 a}$ begins with formation of molecular complex MC1, which is slightly stabilized by only $1.6 \mathrm{kcal} \mathrm{mol}^{-1}$ with respect to the separated reagents. From MC1, the activation energy associated with TS1 is $18.0 \mathrm{kcal} \mathrm{mol}^{-1}$, the reaction being exothermic by $25.8 \mathrm{kcal} \mathrm{mol}^{-1}$. In turn, the relative energy of the TS3 with respect to separated reagents is $16.6 \mathrm{kcal} \mathrm{mol}^{-1}$ for DA reaction $\mathbf{1 a}$ with naphthalene $\mathbf{2 b}$. It is worth to mention that 


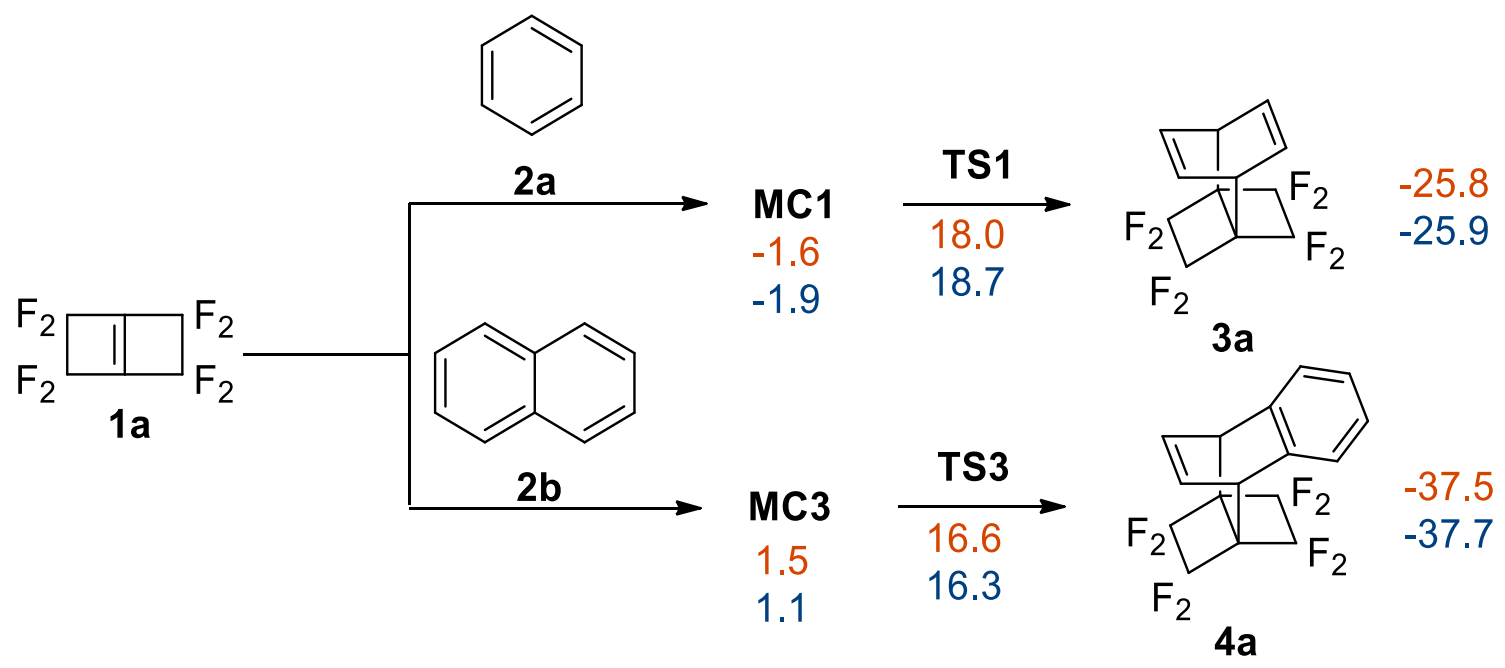

Scheme 5 DA reaction between perfluorobicyclo[2.2.0]hex-1(4)-ene 1a and 2a-b. MPWB1K/6-31G(d,p) relative energies to the separated reagents, in benzene, in orange, and in gas phase, in blue, are given in $\mathrm{kcal} \mathrm{mol}^{-1}$

Table 3 MPWB1K(PCM)/6-

$311 \mathrm{G}(\mathrm{d}, \mathrm{p})$ relative $^{\mathrm{a}}$ enthalpies, Gibbs free energy ( $\Delta \mathrm{H}$ and $\Delta \mathrm{G}$, in $\left.\mathrm{kcal} \cdot \mathrm{mol}^{-1}\right)$ and entropies $\left(\Delta \mathrm{S}\right.$, in cal $\left.\cdot \mathrm{mol}^{-1} \cdot \mathrm{K}^{-1}\right)$, computed at $393 \mathrm{~K}$ in benzene, for the stationary points involved in the DA reactions between perfluorobicyclo[2.2.0] hex-1(4)-ene 1a and $\mathbf{2 a - b}$

\begin{tabular}{llll}
\hline & $\Delta \mathrm{H}$ & $\Delta \mathrm{G}$ & $\Delta \mathrm{S}$ \\
\hline $\mathrm{MC} 1$ & -2.2 & 9.6 & -39.6 \\
TS1 & 17.4 & 32.3 & -49.7 \\
3a & -26.4 & -9.1 & -58.1 \\
MC3 & -2.1 & 10.0 & -40.7 \\
TS3 & 16.0 & 29.8 & -46.1 \\
4a & -38.1 & -20.9 & -57.8 \\
\hline
\end{tabular}

the main factor responsible for higher activation energies of TS1 and TS3 and less favorable values for the formation of 3a and $\mathbf{4 a}$ is associated with the loss of aromatic character along the path evading DA reactions with aromatic species. DA reactions of $\mathbf{1 a}$ with $\mathbf{2} \mathbf{a}-\mathbf{b}$ in the gas phase proceed also according to the one-step mechanism. The activation energy for TS1 (18.7 kcal mol${ }^{-1}$ ) is slightly higher compared to the reaction in benzene environment. In turn, in the case of reactions $\mathbf{1 a}$ with $\mathbf{2 b}$, we observe lower activation energy, $16.3 \mathrm{kcal} \mathrm{mol}^{-1}$ (Scheme 5).

Values of relative enthalpies, Gibbs free energy and entropies of stationary points involved in the DA reaction of $\mathbf{1 a}$ with $\mathbf{2 a - b}$ are summarized in Table 3 . Thus, the activation Gibbs free energy associated with the DA reaction 1a with $\mathbf{2 a}$, via TS1, is $32.3 \mathrm{kcal} \mathrm{mol}^{-1}$, the formation of $\mathbf{3 a}$ being exergonic by $9.1 \mathrm{kcal} \mathrm{mol}^{-1}$. In the case of DA reaction $1 \mathrm{a}$ with naphthalene $\mathbf{2 b}$, the Gibbs free energy is $2.5 \mathrm{kcal} \mathrm{mol}^{-1}$ less than the reaction $1 \mathbf{a}$ with $\mathbf{2 a}$. Note that relative energies (Scheme 5) present the same trend that relative enthalpy and Gibbs free energy values (Table 3).

Optimized TSs involved in the DA reactions between 1 and $\mathbf{2 a - b}$, including some selected distances, are given in Fig. 4. At TS1, the distance between the $\mathrm{C} 1$ and $\mathrm{C} 3$, and the C2 and C6 interacting atoms are $2.206 \AA$ and $2.203 \AA$,
Fig. 4 MPWB1K(PCM)/6$311 \mathrm{G}(\mathrm{d}, \mathrm{p})$ optimized geometries for the TSs associated with the DA reaction between perfluorobicyclo[2.2.0]hex-1(4)-ene 1a and $\mathbf{2 a - b}$. Distances are given in angstroms $\AA$

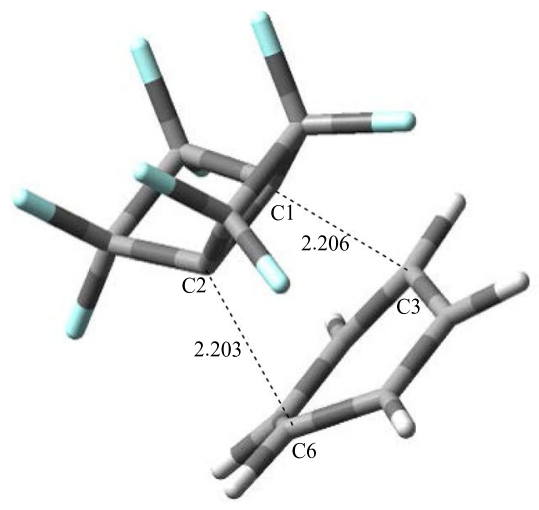

GEDT $=0.37$ TS1

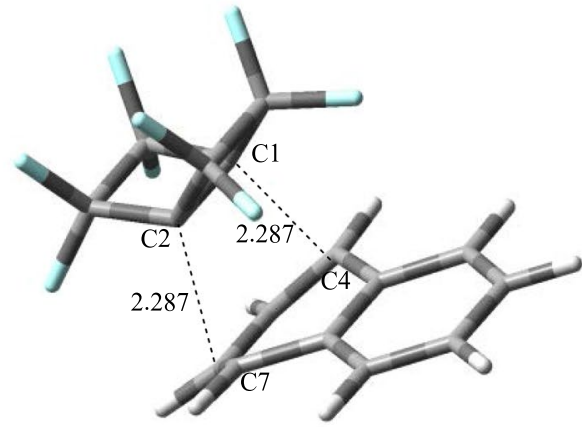

GEDT $=0.34$ TS3 
respectively. These parameters suggest a synchronous bond formation process in which the $\mathrm{C} 1-\mathrm{C} 3$ and $\mathrm{C} 2-\mathrm{C} 6$ bonds are created at the same time. The same dependence is observed for the formation of $\mathrm{C} 1-\mathrm{C} 4$ and $\mathrm{C} 2-\mathrm{C} 7$ bonds in the transition state TS3 in DA reaction between perfluorobicyclo[2.2.0]hex-1(4)-ene 1a and $\mathbf{2 b}$ (Fig. 4). Formation of C1-C4 and C2-C7 bonds in TS3, beginning at the same value for both bonds, and are $2.287 \AA$. The latter shows insignificant differences between the two $\mathrm{C}-\mathrm{C}$ bonding formation process. Hence, it is worth to mention that all these distances, higher than $2.0 \AA$, indicate the $\mathrm{C}-\mathrm{C}$ bond formation have not begun at these TSs [33].

The DA reactions of $\mathbf{1 a}$ and $\mathbf{2 a - b}$ were analyzed by computing the GEDT [33] (Fig. 4). Thus, the GEDT, for the transition state of reaction 1a with benzene $\mathbf{2 a}-\mathbf{b}$, is for TS1 $0.37 \mathrm{e}$ and for TS3 $0.34 \mathrm{e}$, respectively. GEDT values indicate that these reactions show strong polar character of cycloaddition between perfluorobicyclo[2.2.0]hex-1(4)-ene 1a and 2a-b. The DA reaction between perfluorobicyclo[2.2.0]hex1(4)-ene 1a and benzene 2a shows the most polar character. The reaction paths associated with the DA reactions present high values of GEDT; there is not a great effect in the activation energy sue to the aromatic character of the dienes. However, while GEDT is higher, more energetic is the corresponding TS.

The MPWB1K(PCM)/6-311G(d,p) calculations for DA reaction between bicyclo[2.2.0]hex-1(4)-ene $\mathbf{1 b}$ and $\mathbf{2 a - b}$ indicate that these reactions take place according to onestep mechanism (Scheme 6). The relative enthalpies, Gibbs free energy and entropies of the stationary points in the DA reactions of $\mathbf{1 b}$ with $\mathbf{2 a - b}$ are given in Table 4.

The activation energy associated with the DA reaction of bicyclo[2.2.0]hex-1(4)-ene 1b and benzene 2a, begins with the creation of molecular complex MC2. Consequently, the creation of a MC2 entails the drop of energy by $0.5 \mathrm{kcal} \mathrm{mol}^{-1}$. Thereafter, the molecular complex is recast to transition state (TS2), which is associated with an increase in the energy of activation over $23.2 \mathrm{kcal} \mathrm{mol}^{-1}$ (Scheme 6). The formation of the final cycloadduct $\mathbf{3 b}$ is exothermic by
Table 4 MPWB1K(PCM)/6$311 \mathrm{G}(\mathrm{d}, \mathrm{p})$ relative $^{\mathrm{a}}$ enthalpies, Gibbs free energy $(\Delta \mathrm{H}$ and $\Delta \mathrm{G}$, in $\left.\mathrm{kcal} \cdot \mathrm{mol}^{-1}\right)$ and entropies $\left(\Delta \mathrm{S}\right.$, in cal $\left.\cdot \mathrm{mol}^{-1} \cdot \mathrm{K}^{-1}\right)$, computed at $393 \mathrm{~K}$ in benzene, for the stationary points involved in the DA reactions between bicyclo[2.2.0]hex-1(4)ene $\mathbf{1 b}$ and $\mathbf{2 a - b}$

\begin{tabular}{llll}
\hline & $\Delta \mathrm{H}$ & $\Delta \mathrm{G}$ & $\Delta \mathrm{S}$ \\
\hline $\mathrm{MC} 2$ & -0.6 & 11.1 & -39.1 \\
$\mathrm{TS} 2$ & 22.6 & 37.0 & -48.2 \\
3b & -29.6 & -13.7 & -53.3 \\
MC4 & -1.6 & 9.3 & -36.5 \\
TS4 & 17.1 & 31.5 & -48.5 \\
4b & -73.9 & -27.9 & -53.8 \\
\hline
\end{tabular}

$29.0 \mathrm{kcal} \mathrm{mol}^{-1}$. In the case of reaction between $\mathbf{1}$ and $\mathbf{2} \mathbf{b}$, we also observed the similar course of reactions, but we notice a slightly lower energy of activation and for TS4 is $17.7 \mathrm{kcal} \mathrm{mol}^{-1}$. In the case of DA reaction between $\mathbf{1 b}$ and $\mathbf{2 a - b}$, we observe lower energy of activation, for TS2 $23.0 \mathrm{kcal} \mathrm{mol}^{-1}$ and for TS4 $17.3 \mathrm{kcal} \mathrm{mol}^{-1}$. Similar behavior is found in benzene.

The relative enthalpies, entropies and Gibbs free energies of the stationary points involved in the DA reaction bicyclo[2.2.0]hex-1(4)-ene $\mathbf{1 b}$ with $\mathbf{2 a - b}$ are displayed in Table 4 . Thus, the Gibbs free energy associated with the bicyclo[2.2.0] hex-1(4)-ene 1b and benzene 2a, via TS2 is $37.0 \mathrm{kcal} \mathrm{mol}^{-1}$, the formation of the cycloadduct $3 \mathbf{b}$ being exergonic by $13.7 \mathrm{kcal} \mathrm{mol}^{-1}$. In the case of reaction $\mathbf{1 b}$ with $\mathbf{2 b}$, we observe a lower Gibbs free energy, for TS4 $31.5 \mathrm{kcal} \mathrm{mol}^{-1}$ (Table 4). Again, it is important to note that relative energies (Scheme 6) present the same trend that relative enthalpy and Gibbs free energy values (Table 4).

The geometries of TS2 and TS4 are given in Fig. 5. At TS2, the lengths of the two forming bonds are $2.245 \AA$ for $\mathrm{C} 1-\mathrm{C} 3$ and $\mathrm{C} 2-\mathrm{C} 6$. These parameters suggest a synchronous bond formation process in which the $\mathrm{C} 1-\mathrm{C} 3$ and $\mathrm{C} 2-\mathrm{C} 6$ bonds are created at the same time. In the case of transition state TS4, we also observed synchronous bond formation.

Finally, in order to evaluate the polar nature of the DA reaction bicyclo[2.2.0]hex-1(4)-ene 1b with 2a-c, the GEDT [33] at the TSs was analyzed (Fig. 5). The GEDT values computed at the TSs are: 0.05e at TS2 and 0.01e at TS4. These very low values emphasize the nonpolar character of
Scheme 6 DA reaction between bicyclo[2.2.0]hex-1(4)-ene 1b and 2a-b. MPWB1K/6$31 \mathrm{G}(\mathrm{d}, \mathrm{p})$ relative energies to the separated reagents, in benzene, in orange, and in gas phase, in blue, are given in kcal mol${ }^{-1}$

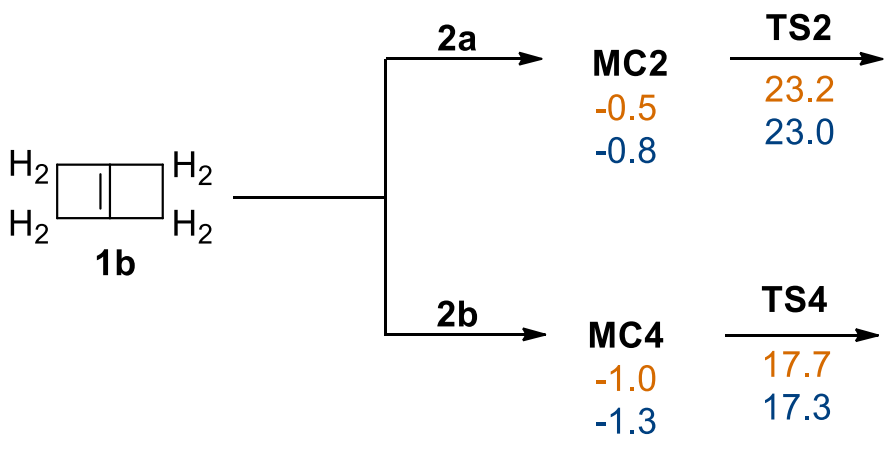

$-29.0$ $-29.4$

$\mathrm{H}_{2}$

3b

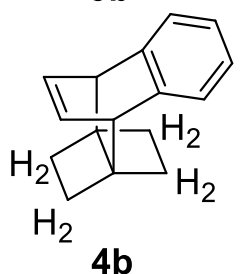


Fig. 5 MPWB1K(PCM)/6$311 \mathrm{G}(\mathrm{d}, \mathrm{p})$ optimized geometries for the TSs associated with the DA reaction between bicyclo[2.2.0]hex-1(4)-ene 1b and $\mathbf{2 a - b}$. Distances are given in angstroms $\AA$

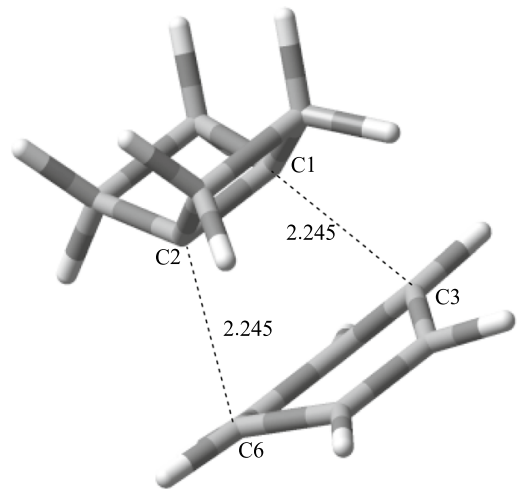

GEDT $=0.05$

TS2

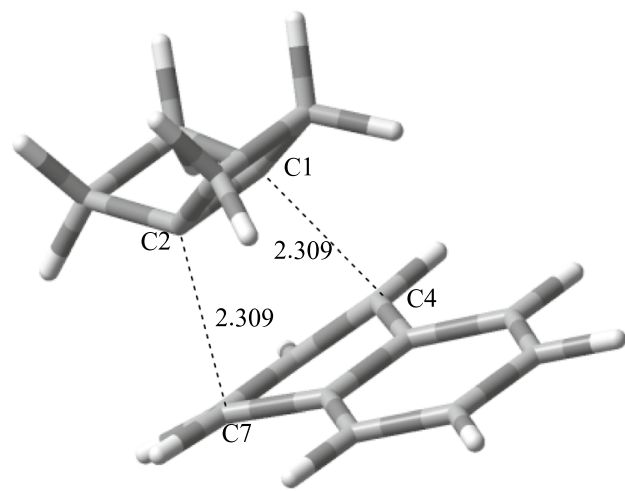

GEDT $=0.01$ TS4 this DA reactions. The nonpolar character of these processes is a result of the marginal electrophilic character of $\mathbf{1 b}$.

\subsection{BET analysis of the DA reactions}

\subsubsection{BET study of the P-DA reaction between perfluorobicyclo[2.2.0]hex-1(4)-ene $1 a$ and benzene $2 a$}

In order to understand the bonding changes along these polar DA reactions, a BET study of the DA reaction perfluorobicyclo[2.2.0]hex-1(4)-ene 1a and benzene 2a was carried out. The molecular mechanism represented by Lewis-like structures result from the ELF topology is shown in Scheme 7. Populations of the most significant valence basins of selected structures of the IRC are collected in Table 5, together with other important parameters.
The bonding changes along this P-DA reaction are characterized by six phases. The topological features of the ELF of the corresponding molecular complex, MC1, which is the first point of the IRC, are very similar to those of the isolated reagents. Along Phase I, a slight depopulation of the $\mathrm{C} 1-\mathrm{C} 2$ bonding region of the 1a fragment by $0.04 \mathrm{e}[\mathrm{V}(\mathrm{C} 1, \mathrm{C} 2)]$ is observed, while the populations around the $\mathrm{C} 3-\mathrm{C} 4, \mathrm{C} 5-\mathrm{C} 6$, $\mathrm{C} 6-\mathrm{C} 7, \mathrm{C} 7-\mathrm{C} 8$ and $\mathrm{C} 8-\mathrm{C} 3$ bonding regions at the benzene moiety remain almost without changes (see Table 5). Phase II begins at the structure S1F. Along this phase, the two $\mathrm{V}(\mathrm{C} 1, \mathrm{C} 2)$ and V'(C1,C2) disynaptic basins present in Phase $I$ have merged into one $\mathrm{V}(\mathrm{C} 1, \mathrm{C} 2)$ disynaptic basins, integrating 3.21 e. Phase III starts at the structure $\mathbf{S 2 F}$. This phase begins with the creation of two $\mathrm{C} 1$ and $\mathrm{C} 2$ pseudoradical centers [52] at the perfluorobicyclo[2.2.0]hex-1(4)-ene 1a moiety, integrating 0.34 e each one (see $\mathrm{V}(\mathrm{C} 1)$ and $\mathrm{V}(\mathrm{C} 2)$ in Table 5, Scheme 7 and Fig. 6) at a length C-C of $2.26 \AA$. The

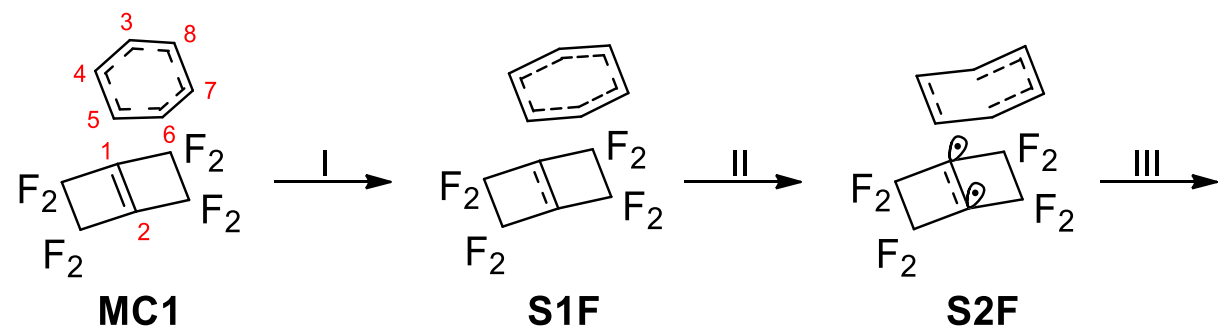

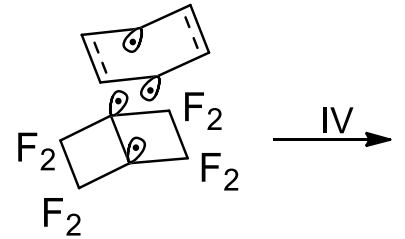

S3F

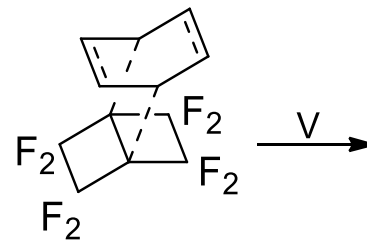

S4F

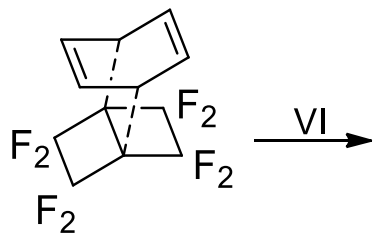

S5F

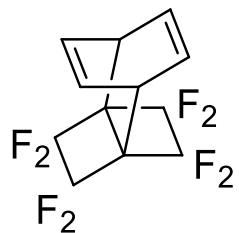

$3 a$

Scheme 7 Simplified representation of the molecular mechanism of the P-DA reaction between perfluorobicyclo[2.2.0]hex-1(4)-ene 1a and benzene $2 \mathbf{a}$ by Lewis-like structures arising from the topological analysis of the ELF along the reaction path 
Table 5 ELF valence basin populations, distances of the forming bonds, MPWB1K(PCM)/6-311G(d,p) GEDT of the IRC structures, S1F - S5F , defining the six phases characterizing the molecular mechanism of the P-DA reaction between perfluorobicyclo[2.2.0]hex-1(4)ene 1a and benzene 2a. MC1, TS1 and the cycloadduct $\mathbf{3 a}$ are also included. Distances are given in angstroms, $\AA$, GEDT values and electron populations in average number of electrons, e, relative energies in $\mathrm{kcal} \cdot \mathrm{mol}^{-1}$

\begin{tabular}{|c|c|c|c|c|c|c|c|c|c|c|c|}
\hline Structures & $1 \mathrm{a}$ & $2 a$ & MC1 & $\mathrm{S} 1 \mathrm{~F}$ & $\mathrm{~S} 2 \mathrm{~F}$ & TS1 & S3F & $\mathrm{S} 4 \mathrm{~F}$ & S5F & & $3 a$ \\
\hline Phases & & & $I$ & & & $I I I$ & $I V$ & & $V$ & $V I$ & \\
\hline $\mathrm{d}(\mathrm{C} 1-\mathrm{C} 3)$ & & & 3.907 & 3.500 & 2.266 & 2.206 & 2.186 & 2.084 & 2.043 & & 1.542 \\
\hline $\mathrm{d}(\mathrm{C} 2-\mathrm{C} 6)$ & & & 3.901 & 3.500 & 2.263 & 2.203 & 2.183 & 2.081 & 2.040 & & 1.542 \\
\hline GEDT & & & -0.02 & 0.20 & 0.35 & 0.37 & 0.28 & 0.25 & 0.26 & & 0.29 \\
\hline $\mathrm{V}(\mathrm{C} 1, \mathrm{C} 2)$ & 1.64 & & 1.41 & 3.12 & 2.62 & 2.49 & 2.45 & 2.29 & 2.20 & & 1.80 \\
\hline $\mathrm{V}^{\prime}(\mathrm{C} 1, \mathrm{C} 2)$ & 1.55 & & 1.74 & & & & & & & & \\
\hline $\mathrm{V}(\mathrm{C} 3, \mathrm{C} 4)$ & & 2.75 & 2.78 & 2.69 & 2.51 & 2.58 & 2.43 & 2.42 & 2.25 & & 1.94 \\
\hline $\mathrm{V}(\mathrm{C} 4, \mathrm{C} 5)$ & & 2.77 & 2.77 & 2.78 & 2,63 & 3.06 & 3.10 & 3.16 & 1.76 & & 1.76 \\
\hline $\mathrm{V}^{\prime}(\mathrm{C} 4, \mathrm{C} 5)$ & & & & & & & & & 1.45 & & 1.69 \\
\hline V(C5,C6) & & 2.79 & 2.75 & 2.69 & 2.51 & 2.58 & 2.43 & 2.42 & 2.25 & & 1.94 \\
\hline V(C6,C7) & & 2.75 & 2.78 & 2.84 & 3.02 & 2.48 & 2.51 & 2.30 & 2.36 & & 2.04 \\
\hline $\mathrm{V}(\mathrm{C} 7, \mathrm{C} 8)$ & & 2.77 & 2.78 & 2.81 & 3.01 & 3.07 & 3.09 & 3.17 & 1.77 & & 1.77 \\
\hline $\mathrm{V}^{\prime}(\mathrm{C} 7, \mathrm{C} 8)$ & & & & & & & & & 1.44 & & 1.69 \\
\hline $\mathrm{V}(\mathrm{C} 8, \mathrm{C} 3)$ & & 2.78 & 2.75 & 2.84 & 2.64 & 2.49 & 2.51 & 2.42 & 2.37 & & 2.04 \\
\hline $\mathrm{V}(\mathrm{C} 1)$ & & & & & 0.34 & 0.57 & 0.62 & & & & \\
\hline $\mathrm{V}(\mathrm{C} 2)$ & & & & & 0.34 & 0.56 & 0.62 & & & & \\
\hline $\mathrm{V}(\mathrm{C} 3)$ & & & & & & & 0.09 & & & & \\
\hline V(C6) & & & & & & & 0.09 & & & & \\
\hline $\mathrm{V}(\mathrm{C} 1, \mathrm{C} 3)$ & & & & & & & & 1.10 & 1.20 & & 1.90 \\
\hline $\mathrm{V}(\mathrm{C} 2, \mathrm{C} 6)$ & & & & & & & & 1.10 & 1.21 & & 2.09 \\
\hline
\end{tabular}
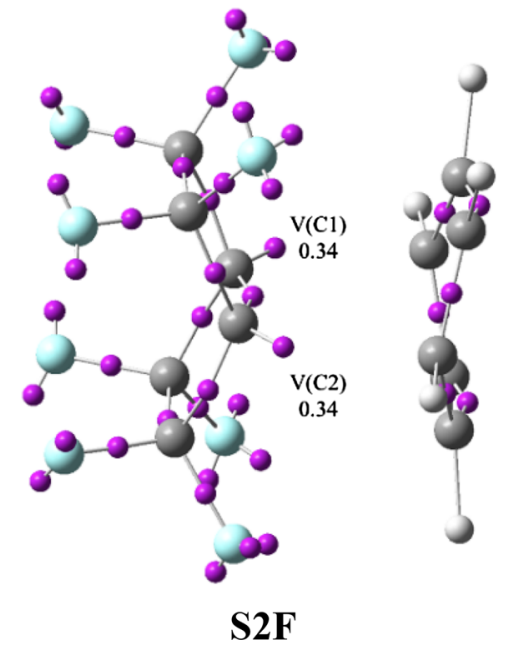

Fig. 6 Attractor positions of the ELF valence basins of the IRC structures $\mathbf{S 2 F}, \mathbf{S 3 F}$ and $\mathbf{S 4 F}$ involved in the $\mathrm{C}-\mathrm{C}$ single bond formation along the DA reaction between perfluorobicyclo[2.2.0]hex-1(4)-ene

formation of these pseudoradical centers is mainly prompted by the depopulation of the $\mathrm{C} 1-\mathrm{C} 2$ bonding region of the 1a fragment by $0.50 \mathrm{e}$ and probably by depopulation of some bonding regions of benzene (see $\mathrm{V}(\mathrm{C} 1, \mathrm{C} 2)$ and $\mathrm{V}(\mathrm{C} 3, \mathrm{C} 4)$ and $\mathrm{V}(\mathrm{C} 5, \mathrm{C} 6)$ in Table 5). At this phase, the TS (TS1) of the reaction is found. The two $\mathrm{V}(\mathrm{C} 1)$ and $\mathrm{V}(\mathrm{C} 2)$ monosynaptic basins have reached populations by $c a 0.57 \mathrm{e}$. Note that the GEDT at TS is the highest, $0.37 \mathrm{e}$, along this reaction. Along Phase IV, which begins at the structure S3F, two new C3 and 1a and benzene 2a. The electron populations, in average number of electrons, is given in e

C6 pseudoradical centers at the benzene 2 a moiety integrating a population of $0.09 \mathrm{e}$, each one, are created (see $\mathrm{V}(\mathrm{C} 3)$ and V(C6) in Table 5, Scheme 7 and Fig. 6). The electron density of these pseudoradical centers is a consequence to the depopulation of the $\mathrm{C} 3-\mathrm{C} 4$ and $\mathrm{C} 5-\mathrm{C} 6$ bonding regions by $c a 0.08 \mathrm{e}[\mathrm{V}(\mathrm{C} 3, \mathrm{C} 4)$ and $\mathrm{V}(\mathrm{C} 5, \mathrm{C} 6)]$. Along this phase, it may be seen that the population associated with the $\mathrm{C} 1$ and $\mathrm{C} 2$ pseudoradical centers [52] increase to $0.62 \mathrm{e}$ [see $\mathrm{V}(\mathrm{C} 1)$ and $\mathrm{V}(\mathrm{C} 2)$ in Table 5). Phase $V$ starts at $\mathbf{S 4 F}$. The most 
relevant topological change is here evidenced: the two pairs of $\mathrm{C} 1, \mathrm{C} 2$ and $\mathrm{C} 3, \mathrm{C} 6$ pseudoradical centers merged into two new $\mathrm{C} 1-\mathrm{C} 3$ and $\mathrm{C} 2-\mathrm{C} 6$ bonding regions [33] with an initial population of 1.10 e each one (see $\mathrm{V}(\mathrm{C} 1, \mathrm{C} 3)$ and $\mathrm{V}(\mathrm{C} 2, \mathrm{C} 6)$ in Table 5, Scheme 7 and Fig. 6). These electron density changes indicate that the formation of the two new $\mathrm{C}-\mathrm{C}$ single bonds begins at a distance of $2.08 \AA$ by sharing the non-bonding electron densities of the two pairs of $\mathrm{C} 1$ and $\mathrm{C} 2$ toward $\mathrm{C} 3$ and $\mathrm{C} 6$ centers. Along this phase while the population associated with $\mathrm{C} 3-\mathrm{C} 4, \mathrm{C} 5-\mathrm{C} 6, \mathrm{C} 6-\mathrm{C} 7$ and $\mathrm{C} 8-\mathrm{C} 3$ bonding regions slightly decreases, those associated with the C4-C5 and C7-C8 bonding regions slightly increase by $\mathrm{ca}$ 0.07 e. Phase VI, begins at S5F and ends at the cycloadduct 3a. At the beginning of this phase, while the $\mathrm{V}(\mathrm{C} 1, \mathrm{C} 3)$ and $\mathrm{V}(\mathrm{C} 2, \mathrm{C6})$ disynaptic basins have reached a population by ca $1.20 \mathrm{e}$, the $\mathrm{V}(\mathrm{C} 4, \mathrm{C} 5)$ and $\mathrm{V}(\mathrm{C} 7, \mathrm{C} 8)$ disynaptic basins present at $\mathbf{S 4 F}$ have been split into two new pairs of disynaptic basins, $\mathrm{V}(\mathrm{C} 4, \mathrm{C} 5)$ and $\mathrm{V}^{\prime}(\mathrm{C} 4, \mathrm{C} 5)$, and $\mathrm{V}(\mathrm{C} 7, \mathrm{C} 8)$ and $\mathrm{V}^{\prime}(\mathrm{C} 7, \mathrm{C} 8)$, respectively, integrating a total population of 3.18 and 3.21 e. Finally, at bicyclic compound 3a, the electron population is relaxed: the $\mathrm{C} 1-\mathrm{C} 3$ and $\mathrm{C} 2-\mathrm{C} 6$ bonding regions integrate $1.90 \mathrm{e}$ and $2.09 \mathrm{e}$. The $\mathrm{C} 4-\mathrm{C} 5$ and $\mathrm{C} 7-\mathrm{C} 8$ bonding regions reach incremented and symmetric populations of $3.45 \mathrm{e}$, acquiring the expected population for double bonds, while that associated with the $\mathrm{C} 1-\mathrm{C} 2, \mathrm{C} 3-\mathrm{C} 4(\mathrm{C} 8)$, C6-C5(C7) bonding regions reaches values around $2.0 \mathrm{e}$, characterizing the expected single bonds at $\mathbf{3 a}$.

Interesting conclusions can be obtained from BET analysis of the P-DA reaction between perfluorobicyclo[2.2.0] hex-1(4)-ene 1a and benzene 2a. (i) This P-DA reaction takes place along six phases. The maximum of GEDT proceeds along Phase III ( 0.37 e). This very high GEDT is a consequence of the strong electrophilic character perfluorobicyclo[2.2.0]hex-1(4)-ene 1a; (ii) TS1 shows the highest energy of the path, $19.6 \mathrm{kcal} \cdot \mathrm{mol}^{-1}$. The activation energy of this reaction is mainly associated with the continuous depopulations of the $\mathrm{C} 1-\mathrm{C} 2, \mathrm{C} 3-\mathrm{C} 4[\mathrm{C} 8]$, C6- $\mathrm{C} 5$ [C7] bonding regions, demanded, at the first time, for the creation of the two $\mathrm{C} 1$ and $\mathrm{C} 2$ pseudoradical centers at the perfluorobicyclo[2.2.0]hex-1(4)-ene moiety 1a. (iii) The formation of the two $\mathrm{C} 1-\mathrm{C} 3$ and $\mathrm{C} 2-\mathrm{C} 6$ single bonds takes place simultaneously at a C-C distance of $2.08 \AA$, by sharing the non-bonding electron densities of the two pairs of $\mathrm{C} 1$ and $\mathrm{C} 2$ toward $\mathrm{C} 3$ and $\mathrm{C} 6$ pseudoradical centers in a 81:19 ratio. (iv) The $\mathrm{C}-\mathrm{C}$ bonding formation process is the P-DA reaction that is completely synchronic. Finally, (v) the P-DA reaction between perfluorobicyclo[2.2.0]hex-1(4)-ene 1a and benzene 2a takes place through a non-concerted onestep mechanism.

\subsubsection{BET study of the P-DA reaction between perfluorobicyclo[2.2.0] hex-1(4)-ene $1 a$ and naphthalene $2 b$}

A BET analysis of the DA reaction perfluorobicyclo[2.2.0] hex-1(4)-ene $\mathbf{1 a}$ and naphthalene $\mathbf{2 b}$ was performed. Lewislike structures resulting from the ELF topology representing the mechanism are shown in Scheme 8. Populations of the most significant valence basins of selected structures of the IRC and other important parameters are given in Table 6.

The bonding changes along this P-DA reaction are characterized by six phases. The topological features of the ELF of the corresponding molecular complex, MC3, being the first point of the IRC, are very similar to those of the separated reagents $\mathbf{1 a}$ and $\mathbf{2 b}$. Along Phase I, very slight depopulation of the $\mathrm{C} 1-\mathrm{C} 2$ bonding region of the 1a

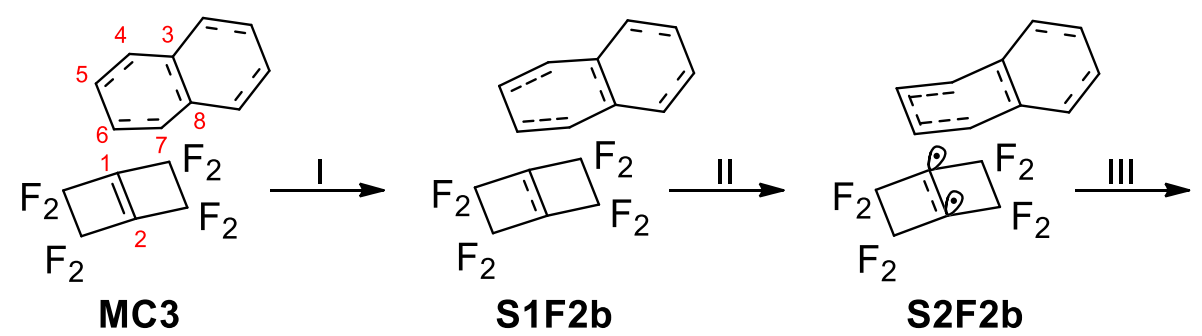

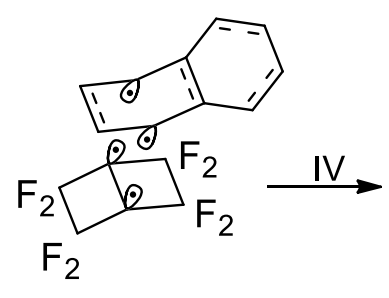

S3F2b
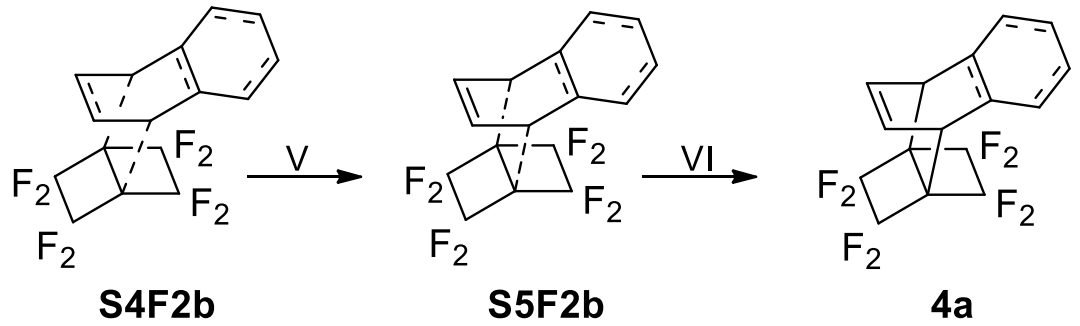

Scheme 8 Simplified representation of the molecular mechanism of the P-DA reaction between perfluorobicyclo[2.2.0]hex-1(4)-ene 1a and naphthalene $\mathbf{2 b}$ by Lewis-like structures arising from the topological analysis of the ELF along the reaction path 
Table 6 ELF valence basin populations, distances of the forming bonds, MPWB1K(PCM)/6-311G(d,p) GEDT of the IRC structures, S1F2b - S5F2b, defining the six phases characterizing the molecular mechanism of the P-DA reaction between perfluorobicyclo[2.2.0]hex-1(4)ene $\mathbf{1 a}$ and naphthalene $\mathbf{2 b}$.

MC3, TS3 and the cycloadduct 4a are also included. Distances are given in angstroms, $\AA$, GEDT values and electron populations in average number of electrons, e, relative energies in $\mathrm{kcal} \cdot \mathrm{mol}^{-1}$

\begin{tabular}{|c|c|c|c|c|c|c|c|c|c|c|}
\hline Structures & $1 \mathrm{a}$ & $2 b$ & MC3 & $\mathrm{S} 1 \mathrm{~F} 2 \mathrm{~b}$ & $\mathrm{~S} 2 \mathrm{~F} 2 \mathrm{~b}$ & TS3 & $\mathrm{S} 3 \mathrm{~F} 2 \mathrm{~b}$ & $\mathrm{~S} 4 \mathrm{~F} 2 \mathrm{~b}$ & $\mathrm{~S} 5 \mathrm{~F} 2 \mathrm{~b}$ & $4 a$ \\
\hline Phases & & & $I$ & & II & III & IV & $V$ & & $V I$ \\
\hline $\mathrm{d}(\mathrm{C} 1-\mathrm{C} 4)$ & & & 3.873 & 3.549 & 2.307 & 2.287 & 2.186 & 2.125 & 2.042 & 1.547 \\
\hline d(C2-C7) & & & 4.147 & 3.551 & 2.307 & 2.287 & 2.186 & 2.125 & 2.043 & 1.547 \\
\hline GEDT & & & -0.02 & 0.11 & 0.33 & 0.34 & 0.32 & 0.28 & 0.24 & 0.26 \\
\hline $\mathrm{V}(\mathrm{C} 1, \mathrm{C} 2)$ & 1.64 & & 1.49 & 3.12 & 2.58 & 2.53 & 2.35 & 2.24 & 2.11 & 1.79 \\
\hline$V^{\prime}(C 1, C 2)$ & 1.55 & & 1.69 & & & & & & & \\
\hline $\mathrm{V}(\mathrm{C} 3, \mathrm{C} 4)$ & & 2.51 & 2.56 & 2.55 & 2.43 & 2.43 & 2.37 & 2.32 & 2.26 & 2.01 \\
\hline $\mathrm{V}(\mathrm{C} 4, \mathrm{C} 5)$ & & 3.03 & 3.06 & 3.04 & 2.71 & 2.69 & 2.49 & 2.41 & 2.29 & 1.98 \\
\hline V(C5,C6) & & 2.54 & 2.54 & 2.58 & 2.90 & 2.93 & 3.04 & 3.11 & 1.75 & 1.78 \\
\hline$V^{\prime}(\mathrm{C} 5, \mathrm{C} 6)$ & & & & & & & & & 1.44 & 1.70 \\
\hline V(C6,C7) & & 3.03 & 3.05 & 3.04 & 2.71 & 2.70 & 2.51 & 2.43 & 2.31 & 1.97 \\
\hline $\mathrm{V}(\mathrm{C} 7, \mathrm{C} 8)$ & & 2.49 & 2.55 & 2.57 & 2.43 & 2.42 & 2.37 & 2.32 & 2.25 & 2.02 \\
\hline $\mathrm{V}(\mathrm{C} 8, \mathrm{C} 3)$ & & 2.63 & 2.59 & 2.62 & 2.73 & 2.71 & 2.74 & 2.76 & 2.78 & 2.85 \\
\hline $\mathrm{V}(\mathrm{C} 1)$ & & & & & 0.40 & 0.48 & 0.77 & & & \\
\hline $\mathrm{V}(\mathrm{C} 2)$ & & & & & 0.40 & 0.48 & 0.77 & & & \\
\hline $\mathrm{V}(\mathrm{C} 4)$ & & & & & & & 0.15 & & & \\
\hline $\mathrm{V}(\mathrm{C} 7)$ & & & & & & & 0.15 & & & \\
\hline $\mathrm{V}(\mathrm{C} 1, \mathrm{C} 4)$ & & & & & & & & 1.10 & 1.30 & 1.89 \\
\hline $\mathrm{V}(\mathrm{C} 2, \mathrm{C} 7)$ & & & & & & & & 1.10 & 1.30 & 1.89 \\
\hline
\end{tabular}

fragment by 0.06 e $[\mathrm{V}(\mathrm{C} 1, \mathrm{C} 2)]$ is observed, while the populations around the $\mathrm{C} 3-\mathrm{C} 4, \mathrm{C} 4-\mathrm{C} 5, \mathrm{C} 5-\mathrm{C} 6, \mathrm{C} 6-\mathrm{C} 7, \mathrm{C} 7-\mathrm{C} 8$ and $\mathrm{C} 8-\mathrm{C} 3$ bonding regions at the naphthalene $\mathbf{2 b}$ fragment remain without observable changes (see Table 6). Phase II begins at the structure S1F2b. Along this phase, the two $\mathrm{V}(\mathrm{C} 1, \mathrm{C} 2)$ and $\mathrm{V}^{\prime}(\mathrm{C} 1, \mathrm{C} 2)$ disynaptic basins present in the above Phase merge into one $\mathrm{V}(\mathrm{C} 1, \mathrm{C} 2)$ disynaptic basins, achieving a population of 3.21 e. Along Phase III, which starts at the structure $\mathbf{S 2 F} 2 \mathbf{b}$, it can be seen the creation of two $\mathrm{C} 1$ and $\mathrm{C} 2$ pseudoradical center [52] at the perfluorobicyclo[2.2.0]hex-1(4)-ene 1a moiety, integrating $0.40 \mathrm{e}$, each one at a C-C length of $2.31 \AA$ (see $\mathrm{V}(\mathrm{C} 1)$ and $\mathrm{V}(\mathrm{C} 2)$ in Table 6, Scheme 8 and Fig. 7). The formation of these pseudoradical centers is mainly encouraged by the depopulation of the $\mathrm{C} 1-\mathrm{C} 2$ bonding region of the $\mathbf{1 a}$ fragment by ca. 0.54 e and by depopulation of C3-C4 and C7-C8 bonding regions by $c a$. 0.12 e and $0.14 \mathrm{e}$, respectively (see $\mathrm{V}(\mathrm{C} 1, \mathrm{C} 2)$ and $\mathrm{V}(\mathrm{C} 3, \mathrm{C} 4)$ and $\mathrm{V}(\mathrm{C} 7, \mathrm{C} 8)$ in Table 6). At this phase, the TS3 of the reaction is found. The two $\mathrm{V}(\mathrm{C} 1)$ and $\mathrm{V}(\mathrm{C} 2)$ monosynaptic basins have reached populations by ca. 0.48 e. Note that the GEDT at TS is the highest, 0.34 e, along this reaction. Along Phase $I V$, which begins at the structure S3F2b, two new C4 and C7 pseudoradical [52] centers are created at the naphthalene $\mathbf{2 b}$ moiety integrating

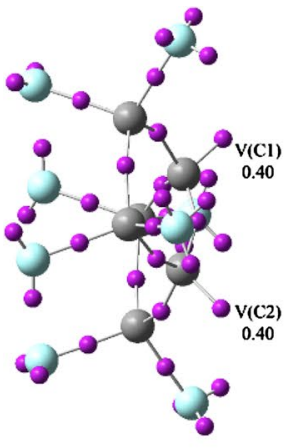

S2F2b

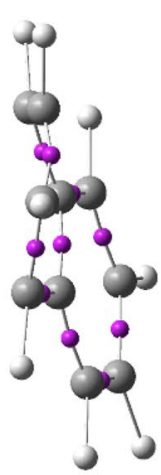

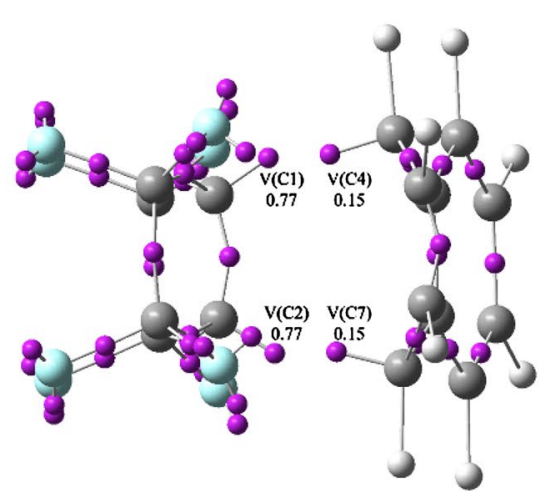

S3F2b

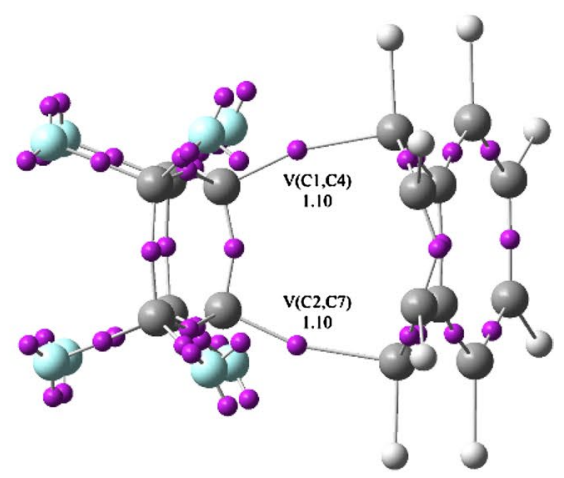

S4F2b
Fig. 7 Attractor positions of the ELF valence basins of the IRC structures S2F2b, S3F2b and S4F2b involved in the $\mathrm{C}-\mathrm{C}$ single bond formation along the DA reaction between perfluorobicyclo[2.2.0]hex- 1(4)-ene 1a and naphthalene $\mathbf{2 b}$. The electron populations, in average number of electrons, are given in $\mathrm{e}$ 
a population of $0.15 \mathrm{e}$, each one (see $\mathrm{V}(\mathrm{C} 4)$ and $\mathrm{V}(\mathrm{C} 7)$ in Table 6, Scheme 8 and Fig. 7). The population attained by these pseudoradical centers mainly is a result of the depopulation of the $\mathrm{C} 4-\mathrm{C} 5$ and $\mathrm{C} 6-\mathrm{C} 7$ bonding regions by $c a .0 .20$ e $(\mathrm{V}(\mathrm{C} 4, \mathrm{C} 5)$ and $\mathrm{V}(\mathrm{C} 6, \mathrm{C} 7))$. Along this phase, it may be seen that the population associated with the $\mathrm{C} 1$ and $\mathrm{C} 2$ pseudoradical centers increase to $0.77 \mathrm{e}$ (see $\mathrm{V}(\mathrm{C} 1)$ and $\mathrm{V}(\mathrm{C} 2)$ in Table 6). Along Phase $V$, which starts at $\mathbf{S 4 F 2 b}$, evidencing an important topological change, the two pairs of $\mathrm{C} 1$, $\mathrm{C} 2$ and $\mathrm{C} 4, \mathrm{C} 7$ pseudoradical centers have merged into two new $\mathrm{C} 1-\mathrm{C} 4$ and $\mathrm{C} 2-\mathrm{C} 7$ bonding regions [33] with an initial population of $1.10 \mathrm{e}$, each one (see $\mathrm{V}(\mathrm{C} 1, \mathrm{C} 4)$ and $\mathrm{V}(\mathrm{C} 2, \mathrm{C} 7)$ in Table 6, Scheme 8 and Fig. 7). The changes of the electron density indicate that the formation of the two new $\mathrm{C}-\mathrm{C}$ single bonds begins at a distance of $2.13 \AA$ by sharing the non-bonding electron densities of the two pairs of $\mathrm{C} 1$ and $\mathrm{C} 2$ toward $\mathrm{C} 4$ and $\mathrm{C} 7$ centers. Along this phase, the population associated with $\mathrm{C} 1-\mathrm{C} 2, \mathrm{C} 3-\mathrm{C} 4, \mathrm{C} 4-\mathrm{C} 5, \mathrm{C} 6-\mathrm{C} 7$ and $\mathrm{C} 7-\mathrm{C} 8$ bonding regions slightly decreases, while those associated with the $\mathrm{C} 5-\mathrm{C} 6$ and $\mathrm{C} 8-\mathrm{C} 3$ bonding regions very slightly increase. Phase VI, begins at S5F2b and finishes at the cycloadduct $4 \mathbf{a}$. At the begin of this phase, while the $\mathrm{V}(\mathrm{C} 1, \mathrm{C} 4)$ and $\mathrm{V}(\mathrm{C} 2, \mathrm{C} 7)$ disynaptic basins have reached a population by $c a .1 .30$ e, the $\mathrm{V}(\mathrm{C} 5, \mathrm{C} 6)$ disynaptic basin is split into two new pairs of disynaptic basins, $\mathrm{V}(\mathrm{C} 5, \mathrm{C} 6)$ and V'(C5,C6) reaching a total population of 3.19 e. Lastly, at compound 4a, the electron population is relaxed: the $\mathrm{C} 1-\mathrm{C} 4$ and $\mathrm{C} 2-\mathrm{C} 7$ bonding regions integrate $1.89 \mathrm{e}$, each one. The $\mathrm{C} 3-\mathrm{C} 4, \mathrm{C} 4-\mathrm{C} 5, \mathrm{C} 6-\mathrm{C} 7$ and $\mathrm{C} 7-\mathrm{C} 8$ bonding regions reach populations by ca. $2.0 \mathrm{e}$, in agreement to the expected single bonds, $\mathrm{C} 5-\mathrm{C} 6$ bonding region attains population of $3.48 \mathrm{e}$, an expected value for double bonds, while $\mathrm{C} 8-\mathrm{C} 3$ bonding region integrates a population of $2.85 \mathrm{e}$, in consistency with delocalized double bonds at the benzene ring of $\mathbf{4 a}$.

From the BET analysis of the P-DA reaction between perfluorobicyclo[2.2.0]hex-1(4)-ene 1a and naphthalene $\mathbf{2 b}$, it may be concluded follows: (i) this is a P-DA reaction, similar to that between 1a and benzene 2a, which also is developed through six different phases. The maximum of GEDT proceeds along Phase III ( 0.34 e), behavior mainly given by the strong electrophilic character perfluorobicyclo[2.2.0] hex-1(4)-ene 1a, $\omega=2.08 \mathrm{eV}$. (ii) The highest energy of the path is found at the TS3, $18.1 \mathrm{kcal} \mathrm{mol}^{-1}$. The activation energy of this reaction is mainly associated with the continuous depopulation of the $\mathrm{C} 1-\mathrm{C} 2$ bonding region, required for the creation of the two $\mathrm{C} 1$ and $\mathrm{C} 2$ pseudoradical centers at the perfluorobicyclo[2.2.0]hex-1(4)-ene 1a moiety. (iii) The formation of the two $\mathrm{C} 1-\mathrm{C} 4$ and $\mathrm{C} 2-\mathrm{C} 7$ single bonds takes place simultaneously at a $\mathrm{C}-\mathrm{C}$ distance of $2.13 \AA$, by sharing the non-bonding electron densities of the two pairs of $\mathrm{C} 1$ and $\mathrm{C} 2$ toward $\mathrm{C} 4$ and $\mathrm{C} 7$ pseudoradical centers in a 81:19 ratio. (iv) The current BET analysis shows many similarities to that observed between 1a and benzene 2a. Note that the formation of the two $\mathrm{C} 1$ and $\mathrm{C} 2$ pseudoradicals in 1a is slightly more advanced in the reaction with benzene $\mathbf{2 a}$ than with naphthalene $\mathbf{2 b}, \mathrm{C}-\mathrm{C}$ length $2.27 \AA$ and $2.31 \AA$, respectively. (vi) At last, this P-DA takes place through a synchronic non-concerted one-step mechanism.

A detailed BET study of the nonpolar DA reaction of bicyclo[2.2.0]hex-1(4)-ene 1 $\mathbf{b}$ with benzene 2a and naphthalene $\mathbf{2 b}$ is given in Supporting Information (see pages S15S22). It is worth to mention here the following concluding remarks for all three DA reactions.

From the BET analysis of the nonpolar DA (N-DA) reaction between bicyclo[2.2.0]hex-1(4)-ene $\mathbf{1 b}$ and benzene 2a, it can be concluded: (i) this N-DA reaction proceeds along six different phases, in a similar mode than that between $\mathbf{1}$ and 2a. The nonpolar character is given by the negligible GEDT observed along the entire process. Note that this result is a fallout of the low electrophilic character of $\mathbf{1 b}$ $(\omega=0.41 \mathrm{eV})$. (ii) TS2 shows the highest energy of this path, $23.2 \mathrm{kcal} \mathrm{mol}^{-1}$. The activation energy of this reaction is mainly associated with the continuous depopulations of the $\mathrm{C} 1-\mathrm{C} 2$ bonding region, required, at the first time, for the creation of the two $\mathrm{C} 1$ and $\mathrm{C} 2$ pseudoradical centers [52] at the bicyclo[2.2.0]hex-1(4)-ene 1b. (iii) Note that even though the activation energies of TS1 and TS2 are in a narrow range $\left(3.6 \mathrm{kcal} \mathrm{mol}^{-1}\right)$; the populations of the $\mathrm{V}(\mathrm{C} 1)$ and $\mathrm{V}(\mathrm{C} 2)$ monosynaptic basins are different, $0.57 \mathrm{e}$ and $0.40 \mathrm{e}$, mainly due to the strong electrophilic character of $1 \mathrm{a}(\omega=2.08 \mathrm{eV})$. (iv) The first two monosynaptic basins appear in compounds $\mathbf{1 a}$ and $\mathbf{1 b}$ at the same $\mathrm{C}-\mathrm{C}$ length of $2.26 \AA$, with similar population, $0.34 \mathrm{e}$. However, these changes, in the reaction of $1 \mathbf{a}$ with $\mathbf{2 a}$, have an energy cost of almost $1.1 \mathrm{kcal} \cdot \mathrm{mol}^{-1}$ lesser than that for $\mathbf{1 b}$ with $\mathbf{2 a}$ (see Supporting Information, pages S15-S18). (v) The formation of the two $\mathrm{C} 1-\mathrm{C} 3$ and $\mathrm{C} 2-\mathrm{C} 6$ single bonds takes place simultaneously at a $\mathrm{C}-\mathrm{C}$ distance of $2.05 \AA$, by sharing the non-bonding electron densities of the two pairs of $\mathrm{C} 1$ and $\mathrm{C} 2$ toward $\mathrm{C} 3$ and $\mathrm{C} 6$ pseudoradical centers in a 65:35 ratio. At the end, (vi) the $\mathrm{C}-\mathrm{C}$ bonding formation process is also non-concerted and fully synchronic.

From the BET study of the DA reaction between bicyclo[2.2.0] hex-1(4)-ene $\mathbf{1 b}$ and naphthalene $\mathbf{2 b}$, the concluding remarks are: (i) this is a N-DA reaction, similar to that between $\mathbf{1 b}$ and benzene 2a. The difference is the current reaction is developed only in five phases. (ii) The highest energy of the path is found at the TS4, $18.7 \mathrm{kcal} \cdot \mathrm{mol}^{-1}$. The activation energy of this reaction is mainly associated with the continuous depopulation of the $\mathrm{C} 1-\mathrm{C} 2$ bonding region required for the creation, in the following phase, the two $\mathrm{C} 1$ and $\mathrm{C} 2$ pseudoradical centers [52] at the bicyclo[2.2.0] hex-1(4)-ene $\mathbf{1 b}$ fragment. (iii) The associated energy cost is very similar to that found for the reaction between 1a and $\mathbf{2 b}$. Note that TS4 does not present formation of pseudoradical centers, in comparison with $\mathbf{T S 3}$, probably due 
to the insignificant GEDT and the marginal electrophilic character of $\mathbf{1 b}(\omega=0.41 \mathrm{eV})$. (iv) Note that the creation of the pseudoradical centers occurs at a $\mathrm{C}-\mathrm{C}$ length of $2.27 \AA$, which is more advanced than that for the reaction of $\mathbf{1 a}$ with $\mathbf{2 b}, 2.31 \AA$. (v) The formation of the two $\mathrm{C} 1-\mathrm{C} 4$ and $\mathrm{C} 2-\mathrm{C} 7$ single bonds takes place simultaneously at a $\mathrm{C}-\mathrm{C}$ distance of $2.05 \AA$, by sharing the non-bonding electron densities of the two pairs of $\mathrm{C} 1$ and $\mathrm{C} 2$ toward $\mathrm{C} 4$ and $\mathrm{C} 7$ pseudoradical centers in a 62:38 ratio. At last, (vi) this N-DA also is completely synchronic in the $\mathrm{C}-\mathrm{C}$ bond forming process (for details see Supporting Information, pages S19-S22).

\section{Conclusions}

The molecular mechanism of the DA reactions of perfluorobicyclo[2.2.0]hex-1(4)-ene 1a and bicyclo[2.2.0]hex-1(4)ene $\mathbf{1 b}$ with benzene $\mathbf{2 a}$ and naphthalene $\mathbf{2 b}$ has been studied using DFT calculations at the MPWB1K/6-311G(d,p) computational level.

Analysis of the CDFT reactivity indices indicates that 1a can be classified as a strong electrophile, $\omega=2.08 \mathrm{eV}$, while 1 b presents $\omega=0.41 \mathrm{eV}$ and $\mathrm{N}=2.95 \mathrm{eV}$, being classified a marginal electrophile and a moderate nucleophile. Clearly, the presence of four fluorine centers in 1a makes it more electrophilic than $\mathbf{1 b}$. The most favorable process will be associated with the two centers interaction between the most electrophilic center of 1a and the most nucleophilic centers of $\mathbf{2 a - b}$. Note that $\mathbf{1 a}$ and $\mathbf{1 b}$ are strained reagents; therefore, it is expected that they react more favorably releasing that strain. On the other hand, $\mathbf{2 a}$ and $\mathbf{2 b}$ are aromatic species, so it is expected they react with their partners minimizing that loss. On the other hand, ELF topological analysis of perfluorobicyclo[2.2.0]hex-1(4)-ene 1a and bicyclo[2.2.0] hex-1(4)-ene 1b, in the most important region, shows the presence of two $\mathrm{V}(\mathrm{C} 1, \mathrm{C} 2)$ and $\mathrm{V}^{\prime}(\mathrm{C} 1, \mathrm{C} 2)$ disynaptic basins, which are related to $\mathrm{C} 1-\mathrm{C} 2$ double bonds in 1a and $1 \mathrm{~b}$ molecules.

Analysis of the stationary points involved in this DA reaction indicates that it takes place through a one-step mechanism which begins with formation of molecular complex. From MC1, the activation energy associated with TS1 is $18.0 \mathrm{kcal} \mathrm{mol}^{-1}$, the reaction being exothermic by $25.8 \mathrm{kcal} \mathrm{mol}^{-1}$. In turn, the relative energies of the TSs with respect to separated reagents are: $16.6 \mathrm{kcal} \mathrm{mol}^{-1}$ for DA reaction 1a with naphthalene $\mathbf{2 b}$ (TS3). The activation energy associated with the DA reaction of bicyclo[2.2.0] hex-1(4)-ene $\mathbf{1 b}$ and benzene $\mathbf{2 a}$, begins also with the creation of molecular complex MC2. Thereafter, the molecular complex is recast to transition state (TS2), which is associated with an increase in the energy of activation over $23.2 \mathrm{kcal} \mathrm{mol}^{-1}$. The formation of the final cycloadduct $\mathbf{3 b}$ is exothermic by $29.0 \mathrm{kcal} \mathrm{mol}^{-1}$. In the case of reaction between $\mathbf{1}$ and $\mathbf{2 b}$, we also observed the similar course of reactions, but we notice a slightly lower energy of activation and for TS4 is $17.7 \mathrm{kcal} \mathrm{mol}^{-1}$. It is worth mentioning that the reactivity order with $\mathbf{1 a}$ is $\mathbf{2 b} \mathbf{b}-\mathbf{2 a}$. The last two behaviors may be related to the loss of the aromatic character of these compounds. On the other hand, the reactivity order with $\mathbf{1 b}$ is $\mathbf{2 b}>\mathbf{2 a}$, even though the activation energies are higher than those observed with 1a, the process is more exothermic. In summary, fluorinated bicyclic 1a is more reactive than non-fluorinated bicyclic $\mathbf{1 b}$ compound. Note that the high energy barriers of perfluorobicyclo[2.2.0]hex-1(4)-ene with benzene and naphthalene are in agreement with the drastic experimental conditions; however, the interest of the current study is to get insight into the reaction mechanism of strained alkene with aromatic species like benzene and naphthalene.

Analysis of the TSs geometries in the case of DA reactions of 1a with $\mathbf{2 a - b}$ indicates that in all reactions, the formation of two bonds are created at the same time, which confirmed the synchronicity one-step process. Also, in the case of DA reactions between $\mathbf{1 b}$ and $\mathbf{2} \mathbf{a}-\mathbf{b}$, the same trend is observed.

BET/ELF analysis of the molecular mechanism associated with the DA reaction of perfluorobicyclo[2.2.0]hex1(4)-ene 1a with benzene 2a indicates that it takes place through a synchronic non-concerted one-step mechanism, which is initialized by rupture of the $\mathrm{C} 1-\mathrm{C} 2$ double bond and next we observed the formation of two $\mathrm{C} 1$ and $\mathrm{C} 2$ pseudoradical centers at the perfluorobicyclo[2.2.0]hex-1(4)-ene 1a moiety. The formation of the two $\mathrm{C} 1-\mathrm{C} 4$ and $\mathrm{C} 2-\mathrm{C} 7$ single bonds takes place simultaneously at a $\mathrm{C}-\mathrm{C}$ distance of $2.13 \AA$, by sharing the non-bonding electron densities of the two pairs of $\mathrm{C} 1$ and $\mathrm{C} 2$ toward $\mathrm{C} 4$ and $\mathrm{C} 7$ pseudoradical centers. Similar relationships are observed in the case of DA reaction $1 \mathbf{a}$ with $\mathbf{2 b}$. In the case of the DA reaction of $\mathbf{1 b}$ with $\mathbf{2 a - b}$, a similar course of reactions was observed. The bonding pattern found here is similar to that found in other DA reactions [53-55]. The knowledge of the molecular mechanism will fully contribute to the design of further syntheses involving benzene.

Acknowledgements Partial support of this research by PL-Grid Infrastructure is gratefully acknowledged. The authors acknowledge the support of the PROM programme no. PPI/PRO/2019/1/00018, which is co-financed by the European Social Fund under the Knowledge Education Development Operational Programme. P.P. also acknowledges continuous support provided by FONDECYT - Chile - through Project No. 1180348. The authors thank Professor R. Jasiński and Professor L. R. Domingo for their valuable comments and suggestions.

Open Access This article is licensed under a Creative Commons Attribution 4.0 International License, which permits use, sharing, adaptation, distribution and reproduction in any medium or format, as long as you give appropriate credit to the original author(s) and the source, provide a link to the Creative Commons licence, and indicate if changes 
were made. The images or other third party material in this article are included in the article's Creative Commons licence, unless indicated otherwise in a credit line to the material. If material is not included in the article's Creative Commons licence and your intended use is not permitted by statutory regulation or exceeds the permitted use, you will need to obtain permission directly from the copyright holder. To view a copy of this licence, visit http://creativecommons.org/licenses/by/4.0/.

\section{References}

1. Bur S, Padwa A (2014) [4+2] Cycloaddition chemistry of substituted Furans. In: Nishiwaki N (ed) Methods and applications of cycloaddition reactions in organic syntheses. Wiley, pp 355-406. https://doi.org/10.1002/9781118778173

2. Balthazor TA, Gaede B, Korte DE, Shieh H-S (1984) Reaction of 1, 1, 1-trichloro-3-nitro-2-propene with furans: a reexamination. J Org Chem 49:4547-4549

3. Anderson WK, Milowsky AS (1985) A retro Diels-Alder synthesis of 3-pyrrolines. J Org Chem 50:5423-5424

4. Jarvest RL, Readshaw SA (1992) Synthesis of some 2, 5-substituted 7-oxabicyclo [2.2.1] heptanes: stereochemistry of DielsAlder adducts of a 3-alkylfuran. Synthesis 10:962-965

5. Batt DG, Jones DG, La Greca S (1991) Regioselectivity in the acid-catalyzed isomerization of 2-substituted 1, 4-dihydro-1, 4-epoxynaphthalenes. J Org Chem 56:6704-6708

6. Kozikowski AP, Floyd WC, Kuniak MP (1977) 1,3-Diethoxycarbonylallene: an active dienophile and ethoxycarbonylketen equivalent in the synthesis of antibiotic C-nucleosides. J Chem Soc Chem Commun. https://doi.org/10.1039/c39770000582

7. Szczepanek A, Jasińska E, Kącka A, Jasiński R (2015) An experimental and quantumchemical study of $[2+3]$ cycloaddition between (Z)-C-(m, m, p-trimethoxyphenyl)- $\mathrm{N}$-(p-methyphenyl)nitrone and (E)-3,3,3-trichloro-1-nitroprop-1-ene: mechanistic aspects. Curr Chem Lett 4:33-44

8. Atherton JCC, Jones S (2003) Diels-Alder reactions of anthracene, 9 -substituted anthracenes and 9,10-disubstituted anthracenes. Tetrahedron 59:9039-9057

9. Dinulescu IG, Avram M, Nenitzescu CD (1960) Dien-Synthesen des 2.3-Dihydro-naphthalins und des Naphthalins mit N-Phenylmaleinimid. Chem Ber 93:1795-1799

10. Lange GL, Neidert E (1973) Photochemistry of 2, 4-Cyclooctadienone I. In Benzene and Toluene. Can J Chem 51:2207-2214

11. Streit U, Bochet ChG (2011) The arene-alkene photocycloaddition. Beilstein J Org Chem 7:525-542

12. He Y, Junk ChP, Lemal DM (2003) Diels-Alder reactions of Perfluorobicyclo [2.2. 0] hex-1 (4)-ene with aromatics. Org Lett 5:2135-2136

13. Houk KN, Nendel M, Wiest O, Storer JW (1997) The vinylcyclopropane-cyclopentene rearrangement: a prototype thermal rearrangement involving competing diradical concerted and stepwise mechanisms. J Am Chem Soc 119:10545-10546

14. Vermeeren P, Brinkhuis F, Hamlin TA, Bickelhaupt MF (2020) How alkali cations catalyze aromatic Diels-Alder reactions. Chem Asian J 15:1167-1174

15. Bickelhaupt FM (1999) Understanding reactivity with Kohn-Sham molecular orbital theory: E2-SN2 mechanistic spectrum and other concepts. J Comput Chem 20:114-128

16. Domingo LR, Pérez P (2020) Lithium Cation-catalyzed benzene Diels-Alder reaction: insights on the molecular mechanism within the molecular electron density theory. J Org Chem 85:13121-13132

17. Domingo LR, Sáez J (2009) Understanding the mechanism of polar Diels-Alder reactions. Org Biomol Chem 7:3576-3583
18. Domingo LR (2016) Molecular electron density theory: a modern view of reactivity in organic chemistry. Molecules 21:1319

19. Domingo LR, Ríos-Gutiérrez M, Pérez P (2020) A molecular electron density theory study of the participation of tetrazines in aza-Diels-Alder reactions. RSC Adv 10:15394-15405

20. Parr RG, Pearson RG (1983) Absolute hardness: companion parameter to absolute electronegativity. J Am Chem Soc 105:7512-7516

21. Parr RG, Yang W (1989) Density functional theory of atoms and molecules. Oxford University Press, New York

22. Krokidis X, Noury S, Silvi B (1997) Characterization of elementary chemical processes by catastrophe theory. J Phys Chem A 101:7277-7283

23. Frisch MJ, Trucks GW, Schlegel HB, Scuseria GE, Robb MA, Cheeseman JR, Montgomery JA, Vreven TJ, Kudin KN, Burant JC, Millam JM, Iyengar SS, Tomasi J, Barone V, Mennucci B, Cossi M, Scalmani G, Rega N, Petersson GA, Nakatsuji H, Hada M, Ehara M, Toyota K, Fukuda R, Hasegawa J, Ishida M, Nakajima Y, Honda O, Kitao O, Nakai H, Klene M, Li X, Knox JE, Hratchian HP, Cross JB, Adamo C, Jaramillo J, Gomperts R, Stratmann RE, Yazyev O, Austin AJ, Cammi R, Pomelli C, Ochterski JW, Ayala PY, Morokuma K, Voth GA, Salvador P, Dannenberg JJ, Zakrzewski VG, Dapprich S, Daniels AD, Strain MC, Farkas MC, Malick DK, Rabuck AD, Raghavachari K, Foresman JB, Ortiz JV, Cui Q, Baboul AG, Clifford S, Cioslowski J, Stefanov BB, Liu G, Liashenko A, Piskorz P, Komaromi I, Martin RL, Fox DJ, Keith T, Al-Laham MA, Peng CY, Nanayakkara A, Challacombe M, Gill PMW, Johnson B, Chen W, Wong MW, Gonzalez C, Pople JA (2016) Gaussian 16 rev A.1 Gaussian Inc, Wallingford CT

24. Zhao Y, Truhlar GD (2004) Hybrid meta density functional theory methods for thermochemistry, thermochemical kinetics, and noncovalent interactions: the MPW1B95 and MPWB1K models and comparative assessments for hydrogen bonding and Van Der Waals interactions. J Phys Chem A 108:6908-6918

25. Fukui K (1970) Formulation of the reaction coordinate. J Phys Chem 74:4161-4163

26. Tapia O (1992) Solvent effect theories: Quantum and classical formalisms and their applications in chemistry and biochemistry. J Math Chem 10:139-181

27. Tomasi J, Persico M (1994) Molecular interactions in solution: an overview of methods based on continuous distributions of the solvent. Chem Rev 94:2027-2094

28. Simkin Y, Sheikhet I (1995) Quantum chemical and statistical theory of solutions: a computational approach. Ellis Horwood, Chichester

29. Cances MT, Mennunci V, Tomasi J (1997) Evaluation of solvent effects in isotropic and anisotropic dielectrics and in ionic solutions with a unified integral equation method: theoretical bases, computational implementation, and numerical applications. J Chem Phys 107:3032-3041

30. Cossi M, Barone V, Cammi R, Tomasi J (1996) Ab initio study of solvated molecules: a new implementation of the polarizable continuum model. Chem Phys Lett 255:327-335

31. Geerlings P, De Proft F, Langenaeker W (2003) Conceptual density functional theory. Chem Rev 103:1793-1874

32. Domingo LR, Ríos-Gutiérrez M, Pérez P (2016) Applications of the conceptual density functional theory indices to organic chemistry reactivity. Molecules 21:748

33. Domingo LR (2014) new C-C bond formation model based on the quantum chemical topology of electron density. RSC Adv 4:32415-32428

34. Reed AE, Weinstock RB, Weinhold F (1985) Natural population analysis. J Chem Phys 83:735-746 
35. Reed AE, Curtiss LA, Weinhold F (1988) Intermolecular interactions from a natural bond orbital, donor-acceptor viewpoint. Chem Rev 88:899-926

36. Parr RG, Szentpaly LV, Liu S (1999) Electrophilicity index. J Am Chem Soc 121:1922-1924

37. Domingo LR, Chamorro E, Perez P (2008) Understanding the reactivity of captodative ethylenes in polar Cycloaddition reactions. A Theoretical Study J Org Chem 73:4615-4624

38. Domingo LR, Pérez P, Sáez JA (2013) Understanding the local reactivity in polar organic reactions through electrophilic and nucleophilic Parr functions. RSC Adv 3:1486-1494

39. Becke AD, Edgecombe KE (1990) A simple measure of electron localization in atomic and molecular-systems. J Chem Phys 92:5397-5403

40. Noury S, Krokidis X, Fuster F, Silvi B (1999) Computational tools for the electron localization function topological analysis. Comput Chem 23:597-604

41. Dennington R, Keith TA, Millam JM (2016) Semichem Inc., Shawnee Mission, KS, Gauss View, Version 6.1, Semichem Inc., Shawnee Mission, KS

42. Ahrens J, Law GBC (2005) ParaView: an end-user tool for large data visualization. Elsevier, Visualization Handbook

43. Ayachit U (2015) The ParaView Guide: a parallel visualization application, Kitware.

44. Kącka-Zych A (2020) Push-pull nitronates in the [3+2] cycloaddition with nitroethylene: molecular electron density theory study. J Mol Graph Model 97:107549

45. Kącka-Zych A (2019) Understanding the molecular mechanism of the rearrangement of internal nitronic ester into nitronorbornene in light of the MEDT study. Molecules 24:462

46. Kącka-Zych A, Jasiński R (2019) Unexpected molecular mechanism of trimethylsilyl bromide elimination from 2-(trimethylsilyloxy)-3-bromo-3-methyl-isoxazolidines. Theor Chem Acc 138:81-86

47. Kącka-Zych A, Ríos-Gutiérrez M, Domingo LR (2019) A molecular electron density theory study of the Lewis acid-catalyzed decomposition reaction of nitroethyl benzoate using aluminum derivatives. J Phys Org Chem 32:e3938
48. Domingo LR, Ríos-Gutiérrez M, Pérez P (2020) Unveiling the Lewis acid catalyzed Diels-Alder reactions through the molecular electron density theory. Molecules 25:2535

49. Domingo LR, Ríos-Gutiérrez M, Pérez P (2020) A molecular electron density theory study of the enhanced reactivity of aza aromatic compounds participating in Diels-Alder reactions. Org Biomol Chem 18:292-304

50. Domingo LR, Aurell MJ, Pérez P, Contreras R (2002) Quantitative characterization of the global electrophilicity power of common diene/dienophile pairs in Diels-Alder reactions. Tetrahedron 58:4417-4423

51. Jaramillo P, Domingo LR, Chamorro E, Pérez P (2008) A further exploration of a nucleophilicity index based on the gas-phase ionization potentials. J Mol Struct THEOCHEM 865:68-72

52. Domingo LR, Chamorro E, Pérez P (2010) Understanding the high reactivity of the Azomethine Ylides in $[3+2]$ cycloaddition reactions. Lett Org Chem 7:432-439

53. Domingo LR, Pérez P, Sáez J (2012) Origin of the synchronicity in bon-formation in polar Diels-Alder reactions. An ELF analysis of the reaction between cyclopentadiene and tetracyanoethylene. Org Biomol Chem 10:3841-3851

54. Domingo LR, Aurell MJ, Pérez P (2014) The mechanism of ionic Diels-Alder reactions. A DFT study of the oxa-Povarov reaction. RSC Adv 4:16567-16577

55. Yepes D, Valenzuela J, Martinez-Araya J, Pérez P, Jaque P (2019) Effect of exchange-correlation functional on the synchronicity/nonsynchronicity in bond formation in Diels-Alder reactions: a reaction force constant analysis. Phys Chem Chem Phys 21:7412-7428

Publisher's Note Springer Nature remains neutral with regard to jurisdictional claims in published maps and institutional affiliations. 